Research Article

\title{
Wind Speed-Independent Two-Source Energy Balance Model Based on a Theoretical Trapezoidal Relationship between Land Surface Temperature and Fractional Vegetation Cover for Evapotranspiration Estimation
}

\author{
Xiao-Gang Wang $\mathbb{D},{ }^{1,2}$ Qing Kang, ${ }^{2}$ Xiao-Hong Chen $\mathbb{D}^{1},{ }^{1}$ Wen Wang $\mathbb{D},{ }^{3}$ and Qing-Hua Fu ${ }^{2}$ \\ ${ }^{1}$ Water Resources and Environment Research Center, Sun Yat-Sen University, Guangzhou 519082, China \\ ${ }^{2}$ The Pearl River Hydraulic Research Institute, Guangzhou 510611, China \\ ${ }^{3}$ State Key Laboratory of Hydrology-Water Resources and Hydraulic Engineering, Hohai University, Nanjing 210098, China
}

Correspondence should be addressed to Xiao-Gang Wang; xiaogang05010@163.com and Wen Wang; w.wang@126.com

Received 17 May 2019; Revised 9 November 2019; Accepted 10 December 2019; Published 14 February 2020

Academic Editor: Hiroyuki Hashiguchi

Copyright (c) 2020 Xiao-Gang Wang et al. This is an open access article distributed under the Creative Commons Attribution License, which permits unrestricted use, distribution, and reproduction in any medium, provided the original work is properly cited.

\begin{abstract}
An accurate estimation of terrestrial evapotranspiration over heterogeneous surfaces using satellite imagery and few meteorological observations remains a challenging task. Wind speed $(u)$, which is known to exhibit high temporal-spatial variation, is a significant constraint in the abovementioned task. In this study, a wind speed-independent two-source energy balance (WiTSEB) model is proposed on the basis of a theoretical land surface temperature $\left(T_{r}\right)$-fractional vegetation coverage $\left(f_{c}\right)$ trapezoidal space and a two-stage evapotranspiration decomposing method. The temperatures in theoretically driest boundaries of the $T_{r}-f_{c}$ trapezoid are iteratively calculated without $u$ by using an assumption of the absence of sensible heat exchange between watersaturated surface and atmosphere in the vertical direction under the given atmospheric condition. The WiTSEB was conducted in HiWATER-MUSOEXE-12 in the middle reaches of the Heihe watershed across eight landscapes by using ASTER images. Results indicate that WiTSEB provides reliable estimates in latent heat flux (LE), with root-mean-square-errors (RMSE) and coefficient of determination of $68.6 \mathrm{~W} \mathrm{~m}^{-2}$ and 0.88 , respectively. The RMSE of the ratio of the vegetation transpiration component to LE is $5.7 \%$. Sensitivity analysis indicates WiTSEB does not aggravate the sensitivity on meteorological and remote sensing inputs in comparison with other two-source models. The errors of estimated $T_{r}$ and observed soil heat flux result in LE overestimation/ underestimation over parts of landscapes. The two-stage evapotranspiration decomposing method is carefully verified by ground observation.
\end{abstract}

\section{Introduction}

Evapotranspiration (ET) plays a significant role in modeling the terrestrial hydrological cycle and energy exchange in a soil-vegetation-atmosphere system. Satellite remote sensing technology potentially provides regional and global ET in an efficient way due to the routine and large spatial scale of observations of land surface properties (e.g., albedo, land surface temperature, $T_{r}$, and vegetation index, VI). Numerous remote sensing models that imply different theoretical complexity and assumptions have been proposed
[1-4]. Among them, models using flux-profile relationship (expressed as vast temperature gradients and aerodynamic resistances) on the basis of the Monin-Obukhov Similarity (MOS) theory and energy balance theory to physically calculate LE (e.g., SEBAL [5], METRIC [6], MOD16 [7, 8], TSEB [9], HTEM [10], and STSEB [11]) or evaporation ratio (e.g., SEBS [12] and TTME [13]), are primarily proposed. Considering the different treatment of land surface, those physically based methods can be further divided into onesource methods (e.g., SEBAL, METRIC, and SEBS) and twosource methods (e.g., TSEB, TTME, HTEM, MOD16, and 
STSEB). One-source methods treat land surface as a "big leaf" and insist turbulent exchange between land surface and atmosphere to occur at a certain height. Although onesource algorithms reported reliable heat fluxes estimate $[6,14,15]$, they often require a precise priori calibration which cannot be guaranteed by diverse range of surface conditions, especially in sparse canopy areas [1-3, 16-20]. Two-source models treat soil and vegetation as different "sources" in heat and water exchange and simulate sensible heat flux, $H$, and LE components differently by component temperatures (i.e., the soil and canopy temperatures), thereby representing an advancement to avoid the priori local calibration in the one-source model [9]. The twosource model is demonstrated to be robust for a wide range of landscape and hydrometeorological conditions [20-24].

Generally, wind speed $u$ (or friction velocity $u^{*}$ ) is the core parameter in calculation of aerodynamic resistance, $r_{a}$ in both one- and two-source physical models is based on flux-profile relationship on the basis of MOS theory, and $u$ (or $u^{*}$ ) considerably affects $H$ and LE estimate. Sánchez et al. [11] emphasized that a $10 \%$ perturbation of $u$ causes the $H$ and LE estimates by the STSEB model perturbing $17 \%$ and $4 \%$. Long and Singh [13] reported that a $20 \%$ perturbation of $u^{*}$ brings an approximately $12.0 \%$ variation in the LE estimate in the TTME model. A $20 \%$ perturbation of $u$ in the HTEM model has resulted in a $7.4 \%$ variation of LE [10]. Wang et al. [4] reported a $25 \%$ increase or decrease in $u$ leads to a $8.6 \%$ increase or a $11.5 \%$ decrease in $H$ estimates in a modified SEBAL model. Webster et al. [25] found that $u$ and $T_{a}$ are nearly as influential as $T_{r}$ for the HTEM and SEBS LE estimates.

However, high-quality grid $u$ (or $u^{*}$ ) is not routinely available. It cannot be remotely sensed. Although reanalysis datasets (e.g., the National Centers for Environmental Prediction Department of Energy (NCEP/DOE), NCEP National Center for Atmospheric Research (NCEP/NCAR), Global Land Data Assimilation System (GLDAS), and China Meteorological Administration Land Data Assimilation System (CLDAS) provide grid $u$, the accuracy essentially depends on the ground observation network, which needs to be improved to match the requirement of ET estimation. Decker et al. [26] indicated that six reanalysis products had RMSE between $1.5 \mathrm{~m} \mathrm{~s}^{-1}$ and $4.5 \mathrm{~m} \mathrm{~s}^{-1}$ against observation of 33 stations in global. In addition, the temporal-spatial scale of the reanalysis data is usually too coarse to be combined with the finer-scale remote-sensing image [27].

There are many studies which attempt to reduce the dependence on $u$. Some researchers transformed $r_{a}$ to substitutive $u$-independent resistances, and $\mathrm{Mu}$ et al. $[7,8]$ and Yao et al. [28] assumed that the $r_{a}$ was parallel to radiative transfer resistance and convective transfer resistance and made $r_{a}$ quantitatively relate to $T_{a}$ and atmospheric pressure or only $T_{a}$. This assumption seems too simple in simulating the significant variation of turbulent flux of heat and momentum [29]. Others introduced a strategy to build a bridge between the actual pixel and a reference site. Qiu et al. [30] assumed that the actual $r_{a}$ was equal to that over a referenced dry bare soil surface. This assumption was inconsistent with the observations by Liu et al. [29] over bare soil and over the maize canopy. Sun et al. [31] subsequently proposed an assumption that $u$ of the actual pixel was equal to that of referenced dry bare soil within the atmospheric surface layer to modify Qiu's method's lack of considering aerodynamic characters of land surface. Nishida et al. [27] employed similar hypothesis and found that the estimation of $u$ was one of the largest error source. The estimated error of $u$ was deduced from the unstable estimation of variables (e.g., $T_{r}, R_{n}$, and soil heat flux, $G_{s}$ ) over referenced dry bare soil surface. Furthermore, equivalent $u$ assumption not takes into account the effect of surface roughness on $u$ [25].

To overcome the dependence on $u$, this paper simulates aerodynamic resistances at given vegetation coverage by means of a referenced water-saturated site with the assumption of the absence of sensible heat exchange between referenced site and upper atmosphere in the vertical direction and proposes a $u$ independent two-source energy balance (WiTSEB) model. Section 2 introduces the WiTSEB model. Section 3 describes the study area and data. Section 4 presents the results. Section 5 discusses the sensitivity, error source, uncertainty analyses, and comparison with other models. Finally, Section 6 provides the conclusions drawn from this study.

\section{Materials and Methods}

The WiTSEB model includes three major modules, i.e., a twosource model framework (Section 2.1), the decomposition of $T_{r}$ via a two-stage ET method $[32,33]$ (Section 2.2), and an iterative process of calculating $\mathrm{LE}_{c}$ and $\mathrm{LE}_{s}$ (Section 2.3). The second module is primarily based on a theoretical $u$ independent $T_{r}-f_{c}$ trapezoidal space modified from a $T_{r}$-VI trapezoidal space proposed by Wang et al. [4] and Wang et al. [34].

2.1. Two-Source Model Framework. The two-source model normally contains layer configuration [9] and patch configuration $[11,35]$. Compared to the layer approach, the patch approach provided comparable estimate accuracy [24] and has an advantage of requiring fewer additional information of the canopy structure to allocate net radiation, $R_{n}$, for the soil and canopy component [11]. Therefore, the WiTSEB adopts the patch framework [11] to simulate energy fluxes:

$$
\begin{aligned}
R_{n} & =f_{c} R_{n c}+\left(1-f_{c}\right) R_{n s}, \\
H & =f_{c} H_{c}+\left(1-f_{c}\right) H_{s}, \\
\mathrm{LE} & =f_{c} \mathrm{LE}_{c}+\left(1-f_{c}\right) \mathrm{LE}_{s}, \\
G & =\left(1-f_{c}\right) G_{s}, \\
R_{n c} & =H_{c}+\mathrm{LE}_{c}, \\
R_{n s} & =H_{s}+\mathrm{LE}_{s}+G_{s},
\end{aligned}
$$

where subscripts $c$ and $s$ represent the vegetation and soil components hereafter, respectively; $R_{n}$ denotes the net radiation $\left(\mathrm{W} \cdot \mathrm{m}^{-2}\right) ; H$ is the sensible heat flux $\left(\mathrm{W} \cdot \mathrm{m}^{-2}\right)$; LE is 
the latent heat flux $\left(\mathrm{W} \cdot \mathrm{m}^{-2}\right) ; G$ and $G_{s}$ are the soil heat flux and soil heat flux of soil component $\left(\mathrm{W} \cdot \mathrm{m}^{-2}\right)$, respectively; $G_{s}$ can be estimated as a fraction $\left(C_{G}\right)$ of $R_{n s}$ [36], where $C_{G}$ varies from 0.2 to 0.5 depending on the soil type and soil moisture, and a constant value of $C_{G}(=0.35)$ is used like other two-source models $[9-11,13] ; f_{c}$ is the fractional vegetation coverage and is calculated by the method recommended by Choudhury et al. [36] but replaces the normalized differential vegetation index (NDVI) by the enhanced vegetation index (EVI) because NDVI results in asymptotic (saturated) signals and scaling problems during high biomass conditions [7].

$$
f_{c}=1-\left(\frac{\mathrm{EVI}_{\max }-\mathrm{EVI}}{\mathrm{EVI}_{\max }-\mathrm{EVI}_{\min }}\right)^{n},
$$

where $\mathrm{EVI}_{\max }$ and $\mathrm{EVI}_{\min }$ are the EVI of the complete vegetation and bare soil surface, respectively, and $n$ is an empirical coefficient which is related to leaf orientation and distribution within a canopy.

$R_{n c}$ and $R_{n s}$ are Calculated as

$$
\begin{aligned}
& R_{n c}=\left(1-\alpha_{c}\right) R_{d}+\varepsilon \varepsilon_{a} \sigma T_{a}^{a}-\varepsilon \sigma T_{c}^{4}, \\
& R_{n s}=\left(1-\alpha_{s}\right) R_{d}+\varepsilon \varepsilon_{a} \sigma T_{a}^{4}-\varepsilon \sigma T_{s}^{4},
\end{aligned}
$$

where $\alpha_{c}$ and $\alpha_{s}$ represent albedos (dimensionless) of vegetation and bare soil, respectively; we assume that the actual pixel $\alpha$ is a weighted composite of $\alpha_{c}$ and $\alpha_{s}$ with $f_{c}$, and $\alpha_{c}$ is fixed as 0.20 [11]; $R_{d}$ is the downward shortwave radiation $\left(\mathrm{W} \cdot \mathrm{m}^{-2}\right)$ and is calculated by the method proposed by Allen et al. [6]; $T_{a}$ is the air temperature $(\mathrm{K}) ; T_{c}$ and $T_{s}$ are the temperatures of canopy and soil $(\mathrm{K})$, respectively; $\varepsilon$ is the land surface emissivity (dimensionless); $\varepsilon_{a}$ is the atmospheric emissivity (dimensionless) and is calculated by the method recommended in Brutsaert [37]; and $\sigma$ is the Boltzmann constant.

$H_{c}$ and $H_{s}$ are calculated as follows:

$$
\begin{aligned}
& H_{c}=\rho C_{p} \frac{T_{c}-T_{a}}{r_{a c}}, \\
& H_{s}=\rho C_{p} \frac{T_{s}-T_{a}}{r_{a s}+r_{s s}},
\end{aligned}
$$

where $\rho$ is the air density $\left(\mathrm{kg} \cdot \mathrm{m}^{-3}\right), C_{p}$ is the air specific heat at a constant pressure $\left(1004 \mathrm{~J} \mathrm{~K}^{-1} \mathrm{~kg}^{-1}\right)$, and $r_{a c}$ is the aerodynamic resistance $\left(\mathrm{s} \mathrm{m}^{-1}\right)$ to heat transfer between meteorological observation height $z(\mathrm{~m})$ and vegetation surface; it is expressed as

$$
r_{a c}=\frac{1}{k U_{c}^{*}}\left(\ln \left(\frac{z-d}{z_{0 h c}}\right)-\varphi_{h}\left(\frac{z-d}{L}\right)+\varphi_{h}\left(\frac{z_{0 h c}}{L}\right)\right),
$$

where $k$ is the Von Karman constant $(=0.41)$; $d$ is the zerodisplacement height (m) and is equal to $2 / 3 h$, where $h$ is the vegetation height $(\mathrm{m}) ; U_{c}^{*}$ is the friction wind speed of the canopy surface; $L$ is the Monin-Obukhov length (m); $\varphi_{h}$ and $\varphi_{m}$ are the stability functions for heat and momentum, calculated according to the value of $L$; and $z_{0 h c}$ is the canopy roughness length for heat $(\mathrm{m})$ and is calculated by the canopy roughness length for momentum $\left(z_{0 m c}\right)$ and a dimensionless parameter $\left(k B_{c}^{-1}\right)$, i.e., $z_{0 m c} / \exp \left(k B_{c}^{-1}\right)$, where the $k B_{c}^{-1}$ is calculated with the approach proposed by Brutsaert [37]:

$$
k B_{c}^{-1}=\frac{k C_{d}}{4 C_{t} U x\left(1-e^{-n / 2}\right)},
$$

where $C_{d}$ is the drag coefficient of the foliage elements and sets to 0.2 [38], $C_{t}$ is the heat transfer coefficient of the leaf, and $U x$ is a function of nondimensional drag area density.

$r_{a s}$ is the aerodynamic resistance $\left(\mathrm{s} \mathrm{m}^{-1}\right)$ to heat transfer between $z$ and bare soil surface and is calculated as

$$
r_{a s}=\frac{1}{k U_{s}^{*}}\left(\ln \left(\frac{z-d}{z_{0 h s}}\right)-\varphi_{h}\left(\frac{z-d}{L}\right)\right),
$$

where $U_{s}^{*}$ is the friction wind speed of the soil surface in the canopy and $z_{0 h s}$ is the soil roughness length for heat $(\mathrm{m})$ and is calculated by the soil roughness length for momentum $\left(z_{0 m s}\right)$ and $k B_{s}^{-1}$, where we set $z_{0 m s}$ as $0.01 \mathrm{~m} ; k B_{s}^{-1}$ is calculated as [39]

$$
k B_{s}^{-1}=2.46(\operatorname{Re})^{1 / 4}-2,
$$

where Re is the roughness Reynolds number $\left(=z_{0 m s} u_{s}^{*} / v\right.$, with $v$ being kinematic viscosity of the air).

$r_{s s}$ is the aerodynamic resistance $\left(\mathrm{s} \mathrm{m}^{-1}\right)$ between soil surface in canopy and $z_{0 m s}+d$, which is calculated by the method recommended in Zeng et al. [40]:

$$
r_{s s}=\frac{1}{c_{s} U_{s}^{*}}
$$

where $c_{s}$ is the turbulent transfer coefficient.

\subsection{Decomposition of $T_{r}$ Based on the Trapezoidal Space}

2.2.1. Construction of the Theorical $T_{r}-f_{c}$ Trapezoidal Space without $u$. Wang et al. [34] constructed a theoretical $T_{r}$-VI trapezoidal space (Figure 1(a)) on a pixel basis. Wang et al. [4] further refined the $T_{r}$-VI trapezoidal space to estimate the regional ET of a semiarid watershed. Theoretically, there are four vertexes representing extreme conditions within the trapezoid space; i.e., Point 1 represents a wellwatered vegetation in which the soil moisture of the root zone is sufficient and has a minimum canopy temperature, $T_{c \text {,min }}$; Point 2 represents the water-stressed vegetation in which the soil moisture of the root zone is considerably deficient and has the maximum canopy temperature, $T_{c, \text { max }}$; Point 3 represents the well-watered bare soil that has a minimal soil temperature, $T_{s, \min }$; and Point 4 represents the dry bare soil in which soil evaporation is seriously inhibited and has a maximum soil temperature, $T_{s, \max }$. The temperatures at the four vertices of the $T_{s}$-VI trapezoid are calculated as 


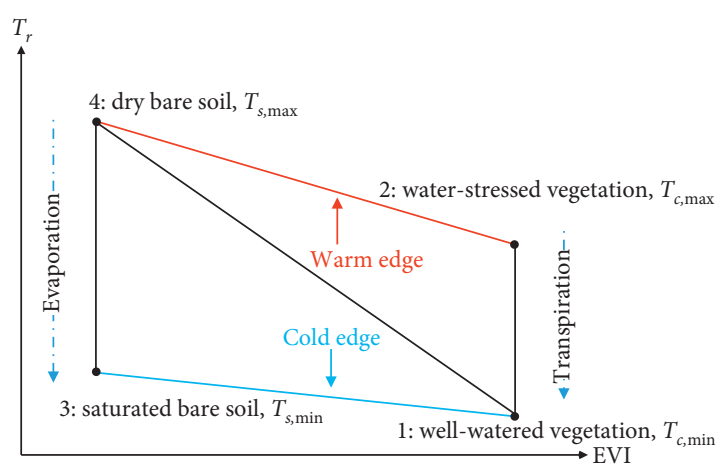

(a)

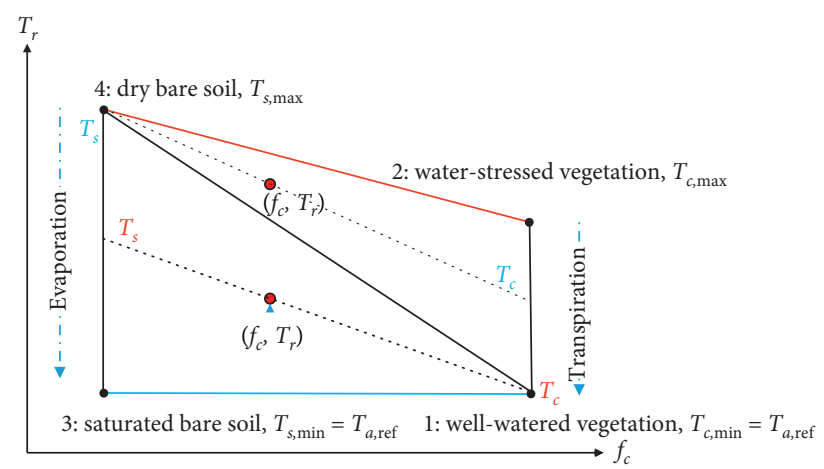

(b)

Figure 1: Trapezoidal space: (a) the $T_{r}$-VI proposed by Wang et al. [34] and Wang et al. [4]; (b) the $T_{r}-f_{c}$ constructed in this study. The $T_{a, \text { ref }}$ is the averaged $T_{a}$ of well-watered landscapes.

$$
\begin{aligned}
& T_{c, \text { } \min }=\frac{\left[r_{a c 1} R_{n c 1} / \rho C_{p}\right] \gamma\left(1+r_{c m} / r_{a c 1}\right)-\mathrm{VPD}}{\Delta+\gamma\left(1+r_{c m} / r_{a c 1}\right)}+T_{a}, \\
& T_{c, \text { max }}=\frac{\left[r_{a c 2} R_{n c 2} / \rho C_{p}\right] \gamma\left(1+r_{c x} / r_{a c 2}\right)-\mathrm{VPD}}{\Delta+\gamma\left(1+r_{c x} / r_{a c 2}\right)}+T_{a}, \\
& T_{s, \text { min }}=\frac{\left[r_{a s 3} R_{n s 3}\left(1-G_{f 3}\right) / \rho C_{p}\right] \gamma-\mathrm{VPD}}{\Delta+\gamma}+T_{a}, \\
& T_{s, \text { max }}=r_{a s 4} R_{n s 4} \frac{\left(1-G_{f 4}\right)}{\rho C_{p}}+T_{a},
\end{aligned}
$$

where subscripts $1,2,3$, and 4 represent the values of vertices plotted in Figure 1, $G_{f}$ denotes the ratios of $G$ to $R_{n}, G_{f 3}$ and $G_{f 4}$ are set to 0.25 and 0.35 , respectively, $r_{c m}$ and $r_{c x}$ are the minimum and maximum canopy resistances $\left(\mathrm{s} \mathrm{m}^{-1}\right)$ and set to 12.5 and 625 , respectively, $\Delta$ is the slope of saturated vapor pressure to air temperature $\left(\mathrm{kPaC}^{-1}\right), \gamma$ is the constant $\left(\mathrm{KPa} \cdot \mathrm{C}^{-1}\right)$, and VPD is the vapor pressure deficit of the air (hPa).

The $T_{r}$-VI trapezoid method has robust theoretical basis, but it requires grid $u$ to calculate $r_{a s}$ and $r_{a c}$, which may show uncertainty especially in heterogeneous landscapes [4]. Here, we further modify the $T_{r}$-VI trapezoid in two aspects to construct a $u$-independent $T_{r}-f_{c}$ trapezoid (Figure 1(b)).

First, we use $f_{c}$ to replace EVI in constructing the trapezoid space to be consistent with the decomposition of $T_{r} . T_{r}$ is typically noted as a mean of the $T_{c}$ and $T_{s}$ weighted by $f_{c}[9]$ :

$$
T_{r}=f_{c} T_{c}+\left(1-f_{c}\right) T_{s} .
$$

Second, we simplify the calculation of the extreme temperatures by employing an assumption that sensible heat flux in the vertical direction at the well-watered edge under given meteorological conditions is negligible. It is equivalent to the assumption in previous studies [13, 41] that wellwatered edge in theory is at equilibrium ET rate when it ignores horizontal advection. This assumption implies the neutral atmospheric conditions of the well-watered edge on basis of MOS theory. Then, we can calculate the $r_{a c 2}$ and $r_{a s 4}$ of neutral atmospheric conditions (i.e., $r_{a c 0}$ and $r_{a s 0}$ ) according to equations (16a) and (16c) without employing $u$ as the input when the $T_{c, \text { min }}$ and $T_{s, \text { min }}$ are known. In practice, we employ the averaged $T_{a}$ of well-watered landscapes as $T_{c, \min }$ and $T_{s, \min }$. The calculation of $r_{a s 4}\left(\right.$ or $\left.r_{a c 2}\right)$ in equation (13) (or equation (11)) can be split into two parts: the $r_{a s 0}$ (or $\left.r_{a c 0}\right)$ and the atmospheric stability correction function, $f\left(\varphi_{m s 4}, \varphi_{h s 4}\right)$, or $f\left(\varphi_{m c 2}, \varphi_{h c 2}\right)$ [29]:

$$
\left\{\begin{array}{l}
r_{a s 4}=r_{a s 0} \times f\left(\varphi_{m s 4}, \varphi_{h s 4}\right), \\
f\left(\varphi_{m s 4}, \varphi_{h s 4}\right)=\left(1-\frac{\varphi_{m s 4}}{\ln \left((z-d) / z_{0 m s 4}\right)}\right) \\
\quad\left(1-\frac{\varphi_{h s 4}}{\ln \left((z-d) / z_{0 h s 4}\right)}\right) .
\end{array}\right.
$$

The procedure for calculating $T_{c, \max }$ and $T_{s, \max }$ on a pixel basis is summarized in the left dash line box of Figure 2, which is divided into two major steps:

(1) Calculate the initial $r_{a c 2}$ and $r_{a s 4}$ (i.e., the $r_{a c 0}$ and $r_{a s 0}$ by means of equations (16a) and (16c), respectively) assuming $f\left(\varphi_{m c 2}, \varphi_{h c 2}\right)=0$ and $f\left(\varphi_{m s 4}, \varphi_{h s 4}\right)=0$.

(2) Iteratively calculate $T_{c, \text { max }}$ and $T_{s, \max }$ (equations (16b) and (16d); $R_{n c 2}$ (equation (8a)), $R_{n s 4}$ (equation (8b)), $H_{c 2}\left(=0.9 R_{n c}\right)$, and $H_{s 4}\left(=R_{n s 4}\left(1-G_{f 4}\right)\right) ; L_{c 2}$ and $L_{c 4}$; $\varphi_{m c 2}, \varphi_{h c 2}, \varphi_{m s 4}$, and $\varphi_{h s 4} ; U_{c 2}^{*}$ (combining equation (9) with equation (11)), $U_{s 4}^{*}$ (combining equation (10) with equation (13)), $k B_{c 2}^{-1}$ (equation (12)), and $k B_{s 4}^{-1}$ (equation (14)); and $f\left(\varphi_{m c 2}, \varphi_{h c 2}\right)$ (the equation similar to equation (18)), $f\left(\varphi_{m s 4}, \varphi_{h s 4}\right)$ (equation (18)), $r_{a c 2}$ (equation (11)), and $r_{a s 4}$ (equation (13)) until the $r_{a c 2}$ and $r_{a s 4}$ are stable, i.e., the difference between two adjacent calculations are smaller than five percent. Normally, the stability can be satisfied within 10 times.

It should be noted that the $H_{c 2}$ is set to $0.9 R_{n c 2}$ because there exists the epidermal cuticle transpiration under extreme drought conditions [42]. 


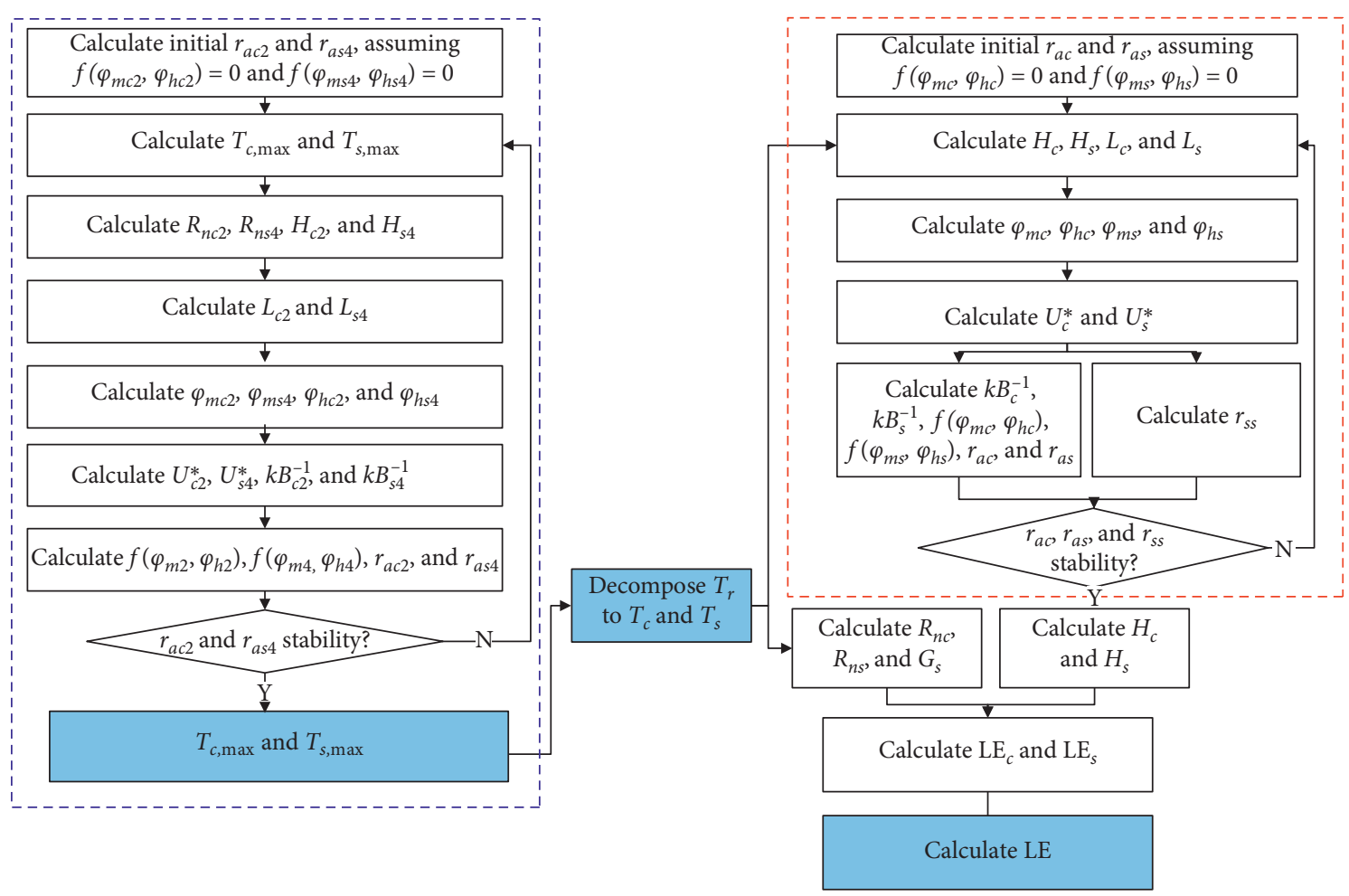

FIgURE 2: Computational procedure of $\mathrm{LE}$ and its components $\left(\mathrm{LE}_{s}\right.$ and $\left.\mathrm{LE}_{c}\right)$ proposed in this study.

2.2.2. Calculation of Component Temperatures. We adopt a two-stage ET method with the $T_{r}-f_{c}$ trapezoidal to estimate $T_{s}$ and $T_{c}$. The two-stage ET method divides the dynamic variation of ET versus soil moisture into two successive phases under a given atmospheric and vegetation conditions, i.e., the soil evaporation stressed stages and the vegetation transpiration stressed stages.

In the soil evaporation stressed stage, where the surface soil moisture $(0-5 \mathrm{~cm})$ gradually decreases, $\mathrm{LE}_{s}$ vary from the maxima to 0 . By contrast, the soil moisture of the root zone remains in the bound that can maintain a canopy transpiring nearly in the potential rate. These variations reflected in the $T_{r}-f_{c}$ trapezoid (Figure $1(\mathrm{~b})$ ) are the temperature variation versus $f_{c}$ of the under triangle. $T_{s}$ increases from the minima $\left(T_{s, \text { min }}\right)$ to the maxima $\left(T_{s, \max }\right)$, and $T_{c}$ remains invariant, which are given by

$$
\left\{\begin{array}{l}
T_{c}=T_{c, \min }, \\
T_{s}=\frac{T_{r}-f_{c} T_{c, \min }}{1-f_{c}} .
\end{array}\right.
$$

In the vegetation transpiration stressed stage, the soil moisture of the root zone substantially decreases and restrains $\mathrm{LE}_{c}$ and $T_{c}$ varies from the minima $\left(T_{c, \text { min }}\right)$ to the maxima $\left(T_{c, \max }\right)$. Moreover, $T_{s}$ maintains $T_{s, \max }$ under extreme deficiency of surface soil moisture. The variation in temperature versus $f_{c}$ in this stage can be reflected by the upper triangle depicted in Figure 1(b). $T_{s}$ and $T_{c}$ can be calculated as

$$
\left\{\begin{array}{l}
T_{s}=T_{s, \text { max }}, \\
T_{c}=\frac{T_{r}-\left(1-f_{c}\right) T_{s, \text { max }}}{f_{c}} .
\end{array}\right.
$$

2.3. Calculation of $L E_{s}, L E_{c}$, and $L E$. The aforementioned assumption is also employed in this part to calculate $H_{c}$ and $H_{s}$, i.e., the $u$-independent $r_{a c 0}$ and $r_{a s 0}$ combining with the $T_{c}$ and $T_{s}$ are used to estimate $H_{c}$ and $H_{s}$ by an iterative process, respectively.

The iterative process of calculation of $H_{c}$ and $H_{s}$ contains two major parts (Figure 2, right dotted box):

(1) Calculate the initial $r_{a c}$ and $r_{a s}$, i.e., the $u$-independent $r_{a c 0}$ and $r_{a s 0}$

(2) Iteratively calculate $H_{c}$ (equation (9)) and $H_{s}$ (equation (10)); $L_{c}$ and $L_{s} ; \varphi_{m c}, \varphi_{h c}, \varphi_{m s}$, and $\varphi_{h s} ; U_{c}^{*}$ (combining equation (9) with equation (11)) and $U_{s}^{*}$ (combining equation (10) with equation (13)); $k B_{c}^{-1}$ (equation (12)), $k B_{s}^{-1}$ (equation (14)), $f\left(\varphi_{m c}, \varphi_{h c}\right)$, $f\left(\varphi_{m s}, \varphi_{h s}\right), r_{a c}$ (equation (11)), and $r_{a s}$ (equation (13)); and $r_{s s}$ (equation (15)) until $r_{a c}, r_{a s}$, and $r_{s s}$ are stable

$\mathrm{LE}_{c}$ and $\mathrm{LE}_{s}$ are calculated as residual energy under each canopy (equation (5)) or soil component (equation (6)). The $\mathrm{LE}$ is estimated as a mean of the $\mathrm{LE}_{c}$ and $\mathrm{LE}_{s}$ weighted by $f_{c}$ through equation (3). 


\section{Study Area and Data}

3.1. Study Area and Ground Observations. The multiscale observation experiment on evapotranspiration over the heterogeneity of the Heihe Watershed Allied Telemetry Experimental Research in 2012 called HiWATERMUSOEXE-12 [43] was conducted between May and September 2012 in the desert-oasis transition zone in the middle reaches of the Heihe watershed (Figure 3 ). The mean annual (1961-2010) air temperature and precipitation of the area are $7.4^{\circ} \mathrm{C}$ and $128.7 \mathrm{~mm}$ [44].

HiWATER-MUSOEXE-12 contains two nested observation matrices, namely, a large area of $30 \mathrm{~km} \times 30 \mathrm{~km}$ and a core area $5.5 \mathrm{~km} \times 5.5 \mathrm{~km}$ located in the Yingke and Daman irrigation district. HiWATER-MUSOEXE-12 equipped 21 automatic weather stations (AWS) and 22 eddy-covariance (EC) stations (two in the DM superstation) and 1 water isotope station (DM superstation) over different land covers (including corn, desert, Gobi, desert steppe, orchard, vegetable, residential, and wetland). Meteorological data, including $T_{a}$, relative humdity $r_{h}$, upward/downward shortwave radiation, upward/downward longwave radiation, net radiation, multilayer soil moisture, and soil temperature, were observed at 21 AWS with an interval of $10 \mathrm{~min} . T_{a}$ and $r_{h}$ were spatially interpolated to the study area with the inverse distance weighting method (IDW) [25]. The soil heat flux $G$ is calculated via the Plate Cal method [45]. This method comprises two parts as follows: the heat-plate flux, which is calculated using $f_{c}$ weighted average of the three heat-plates $(6 \mathrm{~cm}$ below the ground around each flux tower) measurements, and the change of the heat storage in soil, which is calculated by soil temperature change rate, soil moisture, and soil porosity at depths of 2 and $4 \mathrm{~cm}$. $G$ was not calculated at S4, HZZ, and ZY sites given the lack of soil porosity measurement. Quality control on $G$ was conducted primarily on the basis of the rationality of temporal variation of soil temperatures. Vegetation height, $h$, is measured routinely at each AWS station, and the interval of $h$ between two measurements is calculated by linear interpolation.

The preprocessed fluxes from the EC were averaged in $30 \mathrm{~min}$ and typically divided into three quality levels as follows: Level 0 (the quality assessment method for stationarity, $\Delta s t<30$, and the integral turbulent characteristics test, ITC $<30)$, Level $1(\Delta s t<100$ and ITC $<100)$, and Level $2(\Delta s t<100$ and ITC $>100)$. To ensure quality, EC fluxes from Level 2, from suspected instrument drift, and from abnormal $G$ (mainly refers to soil temperature measurement abnormality) were rejected. EC fluxes are generally considered as an energy imbalance. Bowen ratio (BR) and residual energy (RE) are two common methods used for solving the energy imbalance problem in EC systems [46]. The BR method was used in the present study. At the DM station, the ratios of the transpiration component to LE ( $\mathrm{LE}_{\text {canopy }} / \mathrm{LE}$, where $\mathrm{LE}_{\text {canopy }}$ is the canopy transpiration component in a mixed pixel, $=\mathrm{LE}_{c} \times f_{c}$ ) and the evaporation component to $\mathrm{LE}\left(\mathrm{LE}_{\text {soil }} / \mathrm{LE}\right.$, where $\mathrm{LE}_{\text {soil }}$ is the soil evaporation component in a mixed pixel, $=\mathrm{LE}_{s} \times\left(1-f_{c}\right)$ ) were measured using a cavity ring-down spectroscopy (CRDS) water vapor isotope (Model L1102-I, Picarro, Inc.) and represented an average of 13:00-15:00 (local time) [44]; the ET and its evaporation component were calculated via a gradient diffusion method and Craig-Gordon model, respectively.

3.2. Remote-Sensing Data. ASTER (Advanced Spaceborne Thermal Emission and Reflection Radiometer) level $1 \mathrm{~B}$ images on eight cloud-free dates (June 15, June 24, July 10, August 2, August 11, August 18, August 27, and September 3) were acquired from the US Geological Survey website (https://earthexplorer.usgs.gov/). The ASTER provides visible and near-infrared band observations with spatial resolutions of $15 \mathrm{~m}$ between 12:10 and 12:20 (local time). ASTER L1B visible-infrared data were resampled to $90 \mathrm{~m}$ via a nearest neighbor method. $\alpha$ is calculated by fitting narrowband reflectances [47]:

$$
\alpha=0.0771 \rho_{1}+0.3652 \rho_{2}+0.4086 \rho_{3}+0.0178,
$$

where $\rho_{1}, \rho_{2}$, and $\rho_{3}$ represent the reflectances of band1, band 2 , and band 3 covering the visible and near-infrared spectrum, respectively. The EVI was calculated via a twoband method proposed by Jiang et al. [48] who considered that the ASTER sensor did not provide a blue band:

$$
\mathrm{EVI}=2.5 \frac{\rho_{3}-\rho_{2}}{\rho_{3}+2.4 \rho_{2}+1}
$$

Land cover images are acquired via visual interpretation. $T_{r}$ and $\varepsilon$ products were provided by the Cold and Arid Regions Science Data Center; these products were estimated on the basis of temperature-emissivity separation (TES) algorithm [49] using the ASTER thermal infrared band with the spatial resolution of $90 \mathrm{~m}$.

\section{Results}

4.1. Validation of WiTSEB Outputs. The scatterplots of WiTSEB outputs ( $R_{n}, G, H$, and LE) versus ground observations are displayed in Figure 4. The accuracy of WiTSEB outputs are further measured using the mean bias error (MBE), root mean square error (RMSE), and coefficient of determination $\left(r^{2}\right)$ in comparison with ground observations, as listed in Table 1.

$R_{n}$ was best modeled based on equations (1), (8a), and (8b) in terms of the overall RMSE of $31.9 \mathrm{~W} \mathrm{~m}^{-2}$ among the four components of land surface energy balance equations. There was averagely a little underestimation by $5.3 \mathrm{~W} \mathrm{~m}^{-2}$ with an $r^{2}$ of 0.82 . The performance of estimated $R_{n}$ varied with landscapes. That is, it was underestimated at corn, vegetable, and orchard landscapes, but was overestimated at desert steppe, Gobi, residential, and wetland sites. The largest error was occurring over the wetland landscape with an MBE of $64.6 \mathrm{~W} \mathrm{~m}^{-2}$ and an RMSE of $65.1 \mathrm{~W} \mathrm{~m}^{-2}$, which would be probably due to the significant underestimation of $\alpha$.

Due to lack of soil porosity measurement, the accuracy of estimated $G$ was only evaluated at corn, vegetable, orchard, desert, and Gobi sites. $G$ was estimated as a constant of $R_{n s}$ $(=0.35)$, overall yielding an MBE of $-6.4 \mathrm{~W} \mathrm{~m}^{-2}$, an RMSE of 


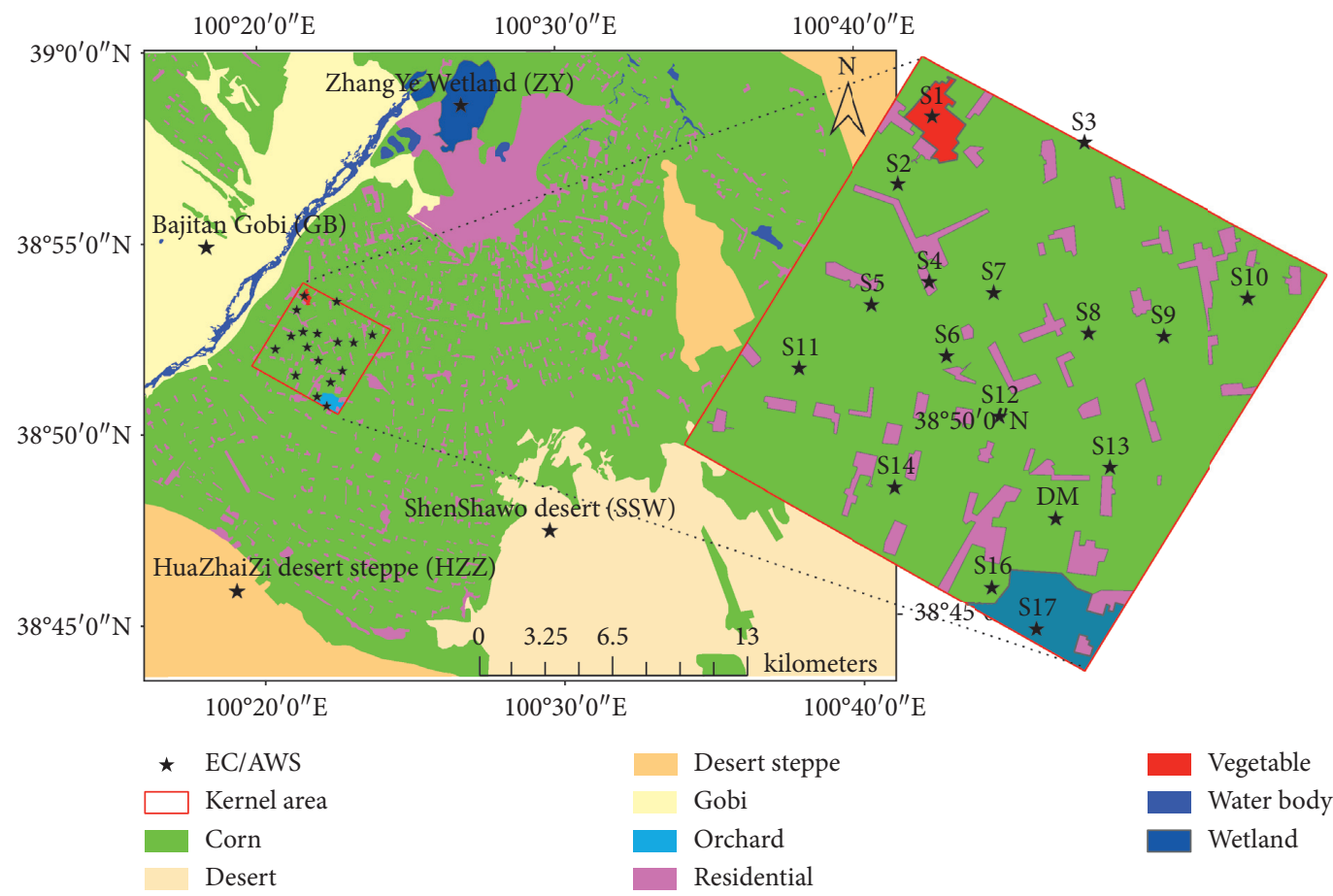

FIgURE 3: Land covers and observation sites in the research site.

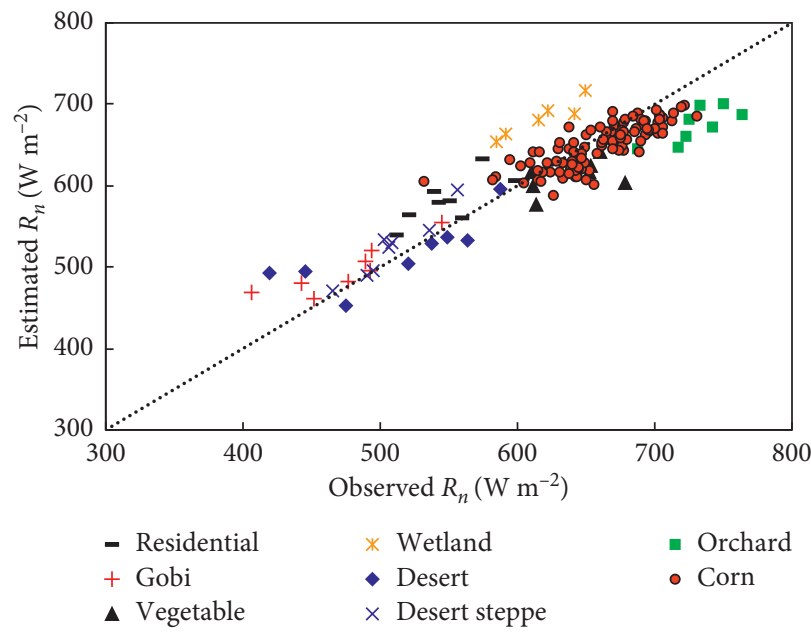

(a)

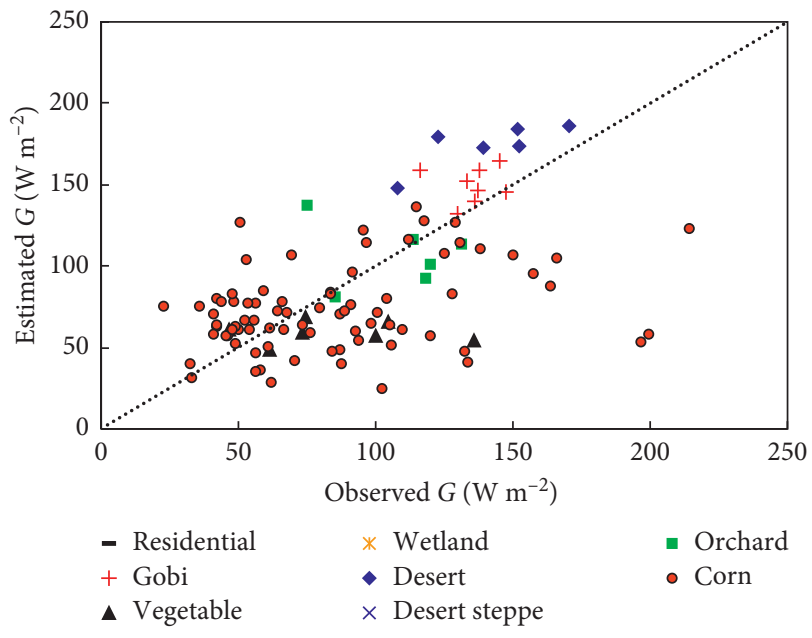

(b)

Figure 4: Continued. 

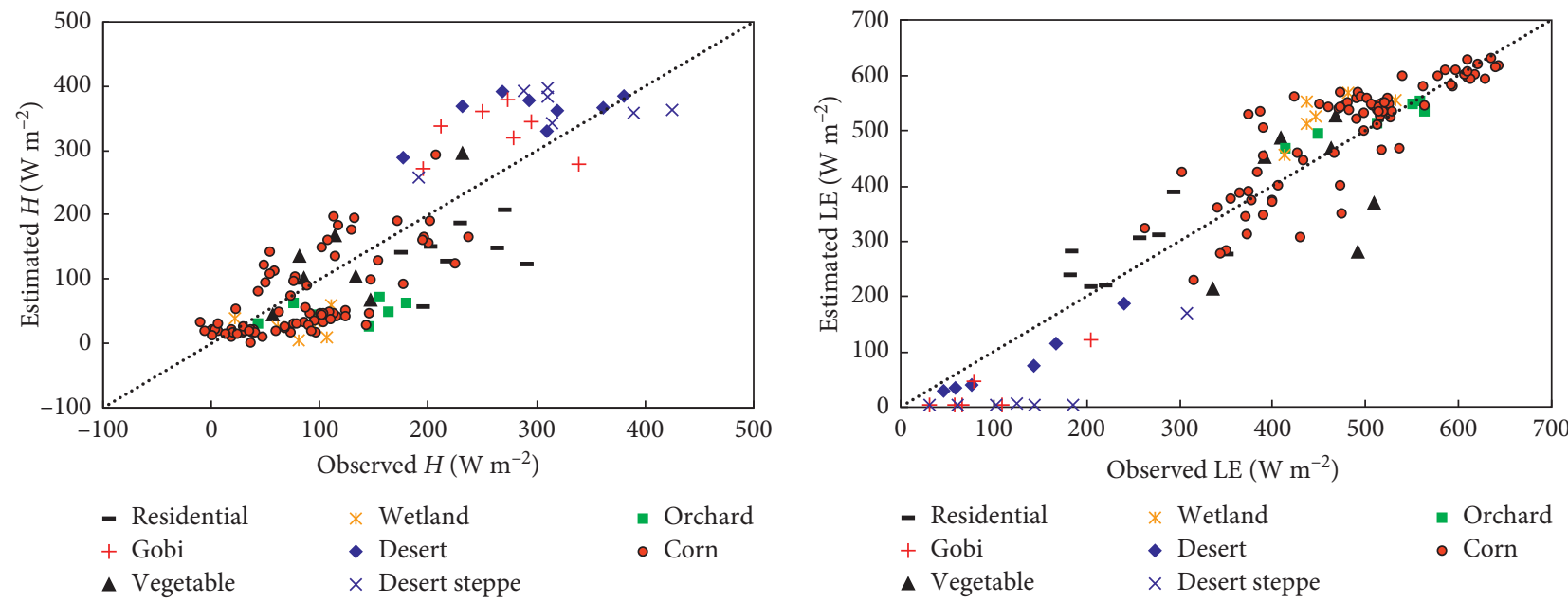

$\begin{array}{lll}\text { - Residential } & * \text { Wetland } & \text { Orchard } \\ + \text { Gobi } & \diamond \text { Desert } & \text { ०Corn } \\ \Delta \text { Vegetable } & \times \text { Desert steppe } & \end{array}$

(c)

(d)

Figure 4: Estimated (a) $R_{n}$, (b) $G$, (c) $H$, and (d) LE vs. ground observations.

TABLE 1: Statistics of energy balance components $\left(R_{n}, G, H\right.$, and LE) modeling accuracies by WiTSEB using ASTER images from eight dates at the HiWATER-MUSOEXE12 at the 21 sites.

\begin{tabular}{|c|c|c|c|c|c|c|}
\hline Flux & LUCC & Observed average $\left(\mathrm{W} \mathrm{m}^{-2}\right)$ & Estimated average $\left(\mathrm{W} \mathrm{m}^{-2}\right)$ & $\operatorname{MBE}\left(\mathrm{W} \mathrm{m}^{-2}\right)$ & $\operatorname{RMSE}\left(\mathrm{W} \mathrm{m}^{-2}\right)$ & $r^{2}$ \\
\hline \multirow{9}{*}{$R_{n}$} & Residential & 550.0 & 581.8 & 31.8 & 37.1 & \multirow{9}{*}{0.82} \\
\hline & Gobi & 474.7 & 496.1 & 21.4 & 28.6 & \\
\hline & Vegetable & 640.3 & 614.4 & -25.9 & 34.5 & \\
\hline & Wetland & 617.7 & 682.3 & 64.6 & 65.1 & \\
\hline & Desert & 512.3 & 517.2 & 4.9 & 35.1 & \\
\hline & Desert steppe & 507.6 & 522.8 & 15.2 & 20.1 & \\
\hline & Orchard & 730.2 & 673.9 & -56.3 & 58.1 & \\
\hline & Corn & 659.5 & 648.3 & -11.2 & 23.6 & \\
\hline & Overall & 631.3 & 626.0 & -5.3 & 31.9 & \\
\hline \multirow{9}{*}{ G } & Residential & - & - & - & - & \multirow{9}{*}{0.22} \\
\hline & Gobi & 135.4 & 149.7 & 14.3 & 19.4 & \\
\hline & Vegetable & 84.4 & 66.7 & -17.7 & 38.9 & \\
\hline & Wetland & NA & NA & NA & NA & \\
\hline & Desert & 129.1 & 173.9 & 44.8 & 50.8 & \\
\hline & Desert steppe & - & - & - & - & \\
\hline & Orchard & 108.7 & 110.1 & 1.4 & 38.3 & \\
\hline & Corn & 86.9 & 73.6 & -12.7 & 45.9 & \\
\hline & Overall & 94.3 & 87.9 & -6.4 & 43.1 & \\
\hline \multirow{9}{*}{$H$} & Residential & 230.3 & 142.7 & -87.6 & 98.5 & \multirow{9}{*}{0.73} \\
\hline & Gobi & 263.1 & 327.1 & 64.0 & 86.8 & \\
\hline & Vegetable & 121.3 & 131.1 & 9.8 & 49.9 & \\
\hline & Wetland & 79.6 & 28.5 & -51.1 & 62.5 & \\
\hline & Desert & 292.2 & 359.1 & 67.1 & 84.3 & \\
\hline & Desert steppe & 318.0 & 357.0 & 39 & 69.9 & \\
\hline & Orchard & 122.2 & 49.3 & -72.9 & 85.4 & \\
\hline & Corn & 85.3 & 69.4 & -15.9 & 50.7 & \\
\hline & Overall & 131.2 & 119.5 & -11.7 & 63.5 & \\
\hline \multirow{9}{*}{ LE } & Residential & 246.4 & 281.3 & 34.9 & 62.5 & \multirow{9}{*}{0.88} \\
\hline & Gobi & 75.8 & 33.7 & -42.1 & 66.7 & \\
\hline & Vegetable & 438.1 & 399.7 & -38.4 & 115.1 & \\
\hline & Wetland & 458.1 & 528.8 & 70.7 & 76.6 & \\
\hline & Desert & 90.9 & 17.0 & -73.9 & 95.0 & \\
\hline & Desert steppe & 136.4 & 28.1 & -108.3 & 118.7 & \\
\hline & Orchard & 509.9 & 517.6 & 7.7 & 35.6 & \\
\hline & Corn & 484.3 & 502.6 & 18.3 & 56.4 & \\
\hline & Overall & 405.4 & 408.1 & 2.7 & 68.6 & \\
\hline
\end{tabular}


43.1 $\mathrm{W} \mathrm{m}^{-2}$, and an $r^{2}$ of 0.22 , compared with tower-based measurements. The fixed fraction strategy might be the principal reason for the low performance in the $G$ estimates.

Reasonable agreement was obtained between the estimated $H$ and the tower-based observations with the MBE and RMSE of -11.7 and $63.5 \mathrm{~W} \mathrm{~m}^{-2}$, respectively. Vegetable and corn sites had relatively small bias of $H$ estimates over in contrast to other landscapes. Negative $H$ measurements are performed at several individual corn sites (Figure 4(c)), whereas their $H$ estimates are positive because the assumption is absence of accounting the effects of horizontal convection.

The estimated LE by WiTSEB has an MBE of $2.7 \mathrm{~W} \mathrm{~m}^{-2}$, an RMSE of $68.6 \mathrm{~W} \mathrm{~m}^{-2}$, and a $r^{2}$ of 0.88 (Table 1). Corn and orchard sites show closer agreement with the ground observation than dry sites, i.e., Gobi, desert, and desert steppe sites, in terms of a smaller bias and a lower RMSE.

Furthermore, we also estimated LE by a model (we named it as TSEB $u$ for convenience) that is identical to WiTSEB, i.e., the patch frame and the two-stage decomposing method, except that TSEB $u$ employes $u$ as the input to calculate the aerodynamic resistances (e.g., $r_{a c 2}, r_{a s 4}, r_{a c}$, $r_{a s}$, and $r_{s s}$ ). The results in Table 2 are the LE-estimated accuracy of TSEB $u$ by using ASTER images from eight dates at the HiWATER-MUSOEXE-12 against the 21 tower observations. Although TSEBu outperforms WiTSEB in terms of RMSE over vegetable, wetland, desert, and desert steppe, it overall shows slightly lower performance, yielding an MBE of $8.0 \mathrm{~W} \mathrm{~m}^{-2}$, an RMSE of $70.7 \mathrm{~W} \mathrm{~m}^{-2}$, and an $r^{2}$ of 0.87 .

4.2. Comparison with Previous Studies. The HiWATERMUSOEXE-12 dataset has been used to evaluate different ET estimation methods in previous studies (Table 3). The RMSE of LE via different methods varies between 17.9 and $133 \mathrm{~W}$ $\mathrm{m}^{-2}$, with a median of $74.8 \mathrm{~W} \mathrm{~m}^{-2}$. Where, TD-TSEB [28] and the nonparametric model [51] have the advantage of removing the dependence on $u$, which provide an RMSE of 89.8 and $133 \mathrm{~W} \mathrm{~m}^{-2}$, respectively. The WiTSEB uses similar inputs and two-source framework as the TD-TSEB but has a lower RMSE (i.e., $41.9 \mathrm{~W} \mathrm{~m}^{-2}$ at the DM station). Although this accuracy comparison is lacking absolute meanings because of assumptions difference, it can illustrate the acceptable accuracy.

4.3. LE Partition. Five days (June 24, July 10, August 2, August 11, and August 27) within the eight dates of ASTER have CRDS water vapor isotope observations at the DM station. The five-day average of canopy transpiration component ratio $\left(\mathrm{LE}_{\text {canopy }} / \mathrm{LE}\right)$ estimation is $84.6 \%$, which is $3.2 \%$ lower than the observation (Table 4 ). A previous study indicated that the CRDS slightly overestimates the ratio of $\mathrm{LE}_{\text {canopy }} / \mathrm{LE}$ [44]. Therefore, the accuracy of $\mathrm{LE}_{\text {canopy }} / \mathrm{LE}$ estimates via the WiTSEB is expected to be high. By contrast, Song et al. [58] adopted a TSEB model using an eight-date observed $T_{r}$ from a Fluke Ti55 thermal infrared imager and other observations (Table 3) to estimate $\mathrm{LE}_{\text {canopy }} / \mathrm{LE}$ and obtained the MBE and RMSE of $1 \%$ and 2\%, respectively. Yang et al. [54] evaluated the performances of the HTEM,
TSEB, and MOD16 models using ASTER images from six dates and determined the MBE of $\mathrm{LE}_{\text {canopy }} / \mathrm{LE}$ at $-1.1 \%$, $4.1 \%$, and $-20.5 \%$, respectively. Yao et al. [28] used Landsat images from five dates to assess the TD-TSEB model and obtained the MBE of $-11.1 \%$.

We assessed the performance of the WiTSEB (Table 4) in $\mathrm{LE}_{\text {soil }}$ (the soil evaporation component in a mixed pixel, $\left.=\mathrm{LE}_{s} \times\left(1-f_{c}\right)\right)$ and $\mathrm{LE}_{\text {canopy }}$ estimates at the $\mathrm{DM}$ station. The results indicated that the MBE (RMSE) of $\mathrm{LE}_{\text {soil }}$, $\mathrm{LE}_{\text {canopy, }}$ and LE are 21.9 (33.7), -0.9 (49.3), and 20.8 (41.9) $\mathrm{W} \mathrm{m}^{-2}$, respectively. By contrast, Song et al. [58] obtained the RMSE of LE at $61 \mathrm{~W} \mathrm{~m}^{-2}$ by using the TSEB model and ground observations. The values of $\mathrm{LE}_{\text {soil }}$, $\mathrm{LE}_{\text {canopy, }}$ and LE underestimated by the TD-TSEB model [28] were $4.2,60.1$, and $63.6 \mathrm{~W} \mathrm{~m}^{-2}$ with the RMSE of 16.5 , 91.3, and $89.8 \mathrm{~W} \mathrm{~m}^{-2}$, respectively.

4.4. Spatial-Temporal Variation. The estimated LE maps for eight dates are exhibited in Figure 5. These maps show significant spatial variations dominated by the spatial distribution of land covers. Generally, LE is large at places of high $f_{c}$ (i.e., wetland, corn, vegetable, and orchard) and low at places with sparse vegetation (i.e., Gobi, desert, and desert steppe). Wetland has the largest LE given sufficient water supply, with an average of $485.4 \mathrm{~W} \mathrm{~m} \mathrm{~m}^{-2}$ over eight dates. Although precipitation is scarce (the cumulative precipitation between June and September in 2012 is $~ 100 \mathrm{~mm}$ ), the orchard, corn, and vegetable-covered areas produce a high LE because of irrigation, with averages of 452.1, 422.1, and $393.3 \mathrm{~W} \mathrm{~m}^{-2}$, respectively. Furthermore, regional irrigation can amplify the spatial difference in soil moisture to increase the spatial variation in LE despite the same land cover type; for example, the LE in June 24 is higher in the northeastern region of the core area (blue box) than in other areas (Figure 5, left column). The soil moisture at a $4 \mathrm{~cm}$ depth is significantly higher in S3, S9, and S10 (36-39\%) than in other corn-covered sites (17-29\%). The LE of the residential area has an average of $262.6 \mathrm{~W} \mathrm{~m}^{-2}$, which is mainly derived from canopy transpiration $\left(174.6 \mathrm{~W} \mathrm{~m}^{-2}\right)$. Owing to water stress (i.e., lack of precipitation and no irrigation), desert, Gobi, and desert steppe provide a small LE, with an average of $44.5,66.3$, and $69.0 \mathrm{~W} \mathrm{~m}^{-2}$, respectively. August 18 is the only date with a two-day antecedent effective precipitation (i.e., daily precipitation is greater than $0.5 \mathrm{~mm}$ ) of $3-5 \mathrm{~mm}$; therefore, Gobi, desert, and desert steppe consistently have a significantly higher LE on August 18 than other dates.

The comparison of LE maps in different dates indicates a temporal variation in LE estimates in areas with high $f_{c}$ due to phenological changes. The averages of LE at the corn and vegetable areas are significantly higher in July and August than in June and September. The orchard and wetland areas also show a temporal variation, but their ranges are smaller than those of the corn and vegetable areas.

In Figure 6, the ratios of $\mathrm{LE}_{\text {canopy }}$ to $\mathrm{LE}\left(\mathrm{LE}_{\text {canopy }} / \mathrm{LE}\right)$ on the desert and desert steppe surfaces are the highest with the average of 0.95 and 0.92 , respectively, over eight dates. This result is because the soil evaporation is extremely stressed given the severe dryness on the soil surface, whereas the 
TABLE 2: Statistics of LE $\left(\mathrm{W} \mathrm{m}^{-2}\right)$ modeling accuracy by TSEB $u$ using ASTER images from eight dates at the HiWATER-MUSOEXE-12 at the 21 sites.

\begin{tabular}{lccccccccc}
\hline Accuracy & Residential & Gobi & Vegetable & Wetland & Desert & Desert steppe & Orchard & Corn & Overall \\
\hline Observed & 246.4 & 75.8 & 438.1 & 458.1 & 90.9 & 136.4 & 509.9 & 484.3 & 405.4 \\
Estimated & 258.7 & 36.0 & 445.6 & 499.5 & 26.4 & 71.8 & 528.3 & 506.5 & 413.4 \\
MBE & 12.3 & -39.8 & 7.5 & 41.4 & -64.5 & -64.6 & 18.4 & 22.2 & 8.0 \\
RMSE & 66.6 & 74.7 & 85.9 & 47.0 & 83.6 & 102.0 & 38.0 & 68.2 & 70.7 \\
\hline
\end{tabular}

TABLE 3: Comparison of LE $\left(\mathrm{W} \cdot \mathrm{m}^{-2}\right)$ estimation accuracies using the HiWATER-MUSOEXE-12 dataset.

\begin{tabular}{|c|c|c|c|c|c|c|c|c|}
\hline \multirow[b]{2}{*}{ Authors } & \multicolumn{5}{|c|}{ Inputs } & \multicolumn{3}{|c|}{ Accuracy } \\
\hline & Model/method & Ground & $\begin{array}{c}\text { Remote } \\
\text { sensing/ } \\
\text { assimilation } \\
\text { product } \\
\end{array}$ & Sites & Images (dates) & RMSE & $\mathrm{MBE}$ & $r^{2}$ \\
\hline $\begin{array}{l}\text { Yao } \\
\text { et al. } \\
{[28]}\end{array}$ & TD-TSEB & $\begin{array}{c}T_{a}, P, \mathrm{VP} \text { (vapor } \\
\text { pressure) }\end{array}$ & $\alpha, \varepsilon, T_{r}, \mathrm{NDVI}$ & $\mathrm{DM}$ & $\begin{array}{l}\text { Landsat (five dates } \\
\text { between } 1 \text { Jun and } \\
30 \text { Sep) }\end{array}$ & 89.8 & -63.6 & 0.81 \\
\hline $\begin{array}{l}\text { Li et al. } \\
{[50]}\end{array}$ & SEBS & $\begin{array}{l}T_{a}, P, u, \text { specific } \\
\text { humidity, } R_{d}, R_{l d}\end{array}$ & $\begin{array}{c}\alpha, \varepsilon, T_{r}, f_{c}, h_{c}, \\
\text { LAI }\end{array}$ & $\begin{array}{c}\text { S1-S17, } \\
\text { ZY, GB, } \\
\text { SSW, HZZ }\end{array}$ & $\begin{array}{l}\text { ASTER (30 May, } 15 \\
\text { Jun, } 24 \text { Jun, } 10 \text { Jul, } 2 \\
\text { Aug, } 8 \text { Aug, } 27 \text { Aug, } \\
\text { and } 3 \text { Sep) }\end{array}$ & $\begin{array}{l}64^{\mathrm{b}} \\
63^{\mathrm{r}}\end{array}$ & $\begin{array}{l}24^{\mathrm{b}} \\
-8^{\mathrm{r}}\end{array}$ & \\
\hline $\begin{array}{l}\text { Pan } \\
\text { et al. } \\
{[51]}\end{array}$ & Non-parametric & & $\begin{array}{c}T_{r}, \alpha, \varepsilon \\
\text { NDVI, } T_{a}, P, \\
r_{h}, R d\end{array}$ & $\begin{array}{l}\text { ZY, S1, S4, } \\
\text { S17, GB, } \\
\text { SSW }\end{array}$ & $\begin{array}{c}\text { MODIS (25 Jun to } 9 \\
\text { Sep) }\end{array}$ & 133 & -59 & 0.48 \\
\hline $\begin{array}{l}\text { Xu et al. } \\
\text { [52] }\end{array}$ & TVDA & $\begin{array}{c}u, T_{a}, r_{h}, P, R_{d}, R_{l d}, \\
T_{r}, \text { LAI }\end{array}$ & & $\mathrm{DM}$ & (7 Jun to 4 Sep) & 116 & 46 & \\
\hline & TSEB & & & & & 132.9 & 82.2 & \\
\hline $\begin{array}{l}\text { Song } \\
\text { et al. } \\
{[53]}\end{array}$ & Two sources + Bayesian & $\begin{array}{c}R_{d}, R_{l d}, u_{i}, T_{a}, r_{h}, P, \\
h_{c}\end{array}$ & $\begin{array}{c}T_{r}, \alpha, \varepsilon \\
\text { NDVI, LAI }\end{array}$ & S1-S17 & $\begin{array}{c}\text { ASTER (10 Jul and } \\
11 \text { Aug) }\end{array}$ & 17.9 & 0.7 & 0.98 \\
\hline $\begin{array}{l}\text { Song } \\
\text { et al. }\end{array}$ & TSEB $_{\mathrm{CT}}$ & $T_{a}, u, P, \mathrm{VP}, R_{d}, \varepsilon$ & NDVI, $T_{r}, \alpha$ & & $\begin{array}{l}\text { ASTER (15 Jun, } 24 \\
\text { Jun, } 10 \text { Jul, } 2 \text { Aug, } \\
11 \text { Aug, } 18 \text { Aug, } 27\end{array}$ & $\begin{array}{l}52^{\mathrm{b}} \\
58^{\mathrm{r}}\end{array}$ & $\begin{array}{c}3^{\mathrm{b}} \\
-21^{\mathrm{r}}\end{array}$ & \\
\hline $\begin{array}{l}\text { et al. } \\
\text { [47] }\end{array}$ & TSEB & $T_{a}, u, P, \mathrm{VP}, R_{d}, \varepsilon$ & NDVI, $T_{r}, \alpha$ & $\mathrm{S1-S17}$ & $\begin{array}{c}\text { Aug, } 3 \text { Sep, and } 12 \\
\text { Sep) }\end{array}$ & $\begin{array}{l}87^{\mathrm{b}} \\
71^{\mathrm{r}}\end{array}$ & $\begin{array}{l}50^{\mathrm{b}} \\
25^{\mathrm{r}}\end{array}$ & \\
\hline $\begin{array}{l}\text { Yang } \\
\text { et al. }\end{array}$ & $\begin{array}{l}\text { HTEM } \\
\text { TSEB }\end{array}$ & $T_{a}$, LAI, $h_{c}, u, f_{c}, r_{h}$, & NDVI, $\alpha, \varepsilon T_{r}$ & $\begin{array}{l}\text { S1-S17, } \\
\text { ZY, GB, }\end{array}$ & $\begin{array}{l}\text { ASTER (10 Jul, } 2 \\
\text { Aug, } 11 \text { Aug, } 18\end{array}$ & $\begin{array}{l}42.3^{\mathrm{r}} \\
49.8^{\mathrm{r}}\end{array}$ & $\begin{array}{c}-15.7^{\mathrm{r}} \\
4.8^{\mathrm{r}}\end{array}$ & $\begin{array}{l}0.88 \\
0.85\end{array}$ \\
\hline$[54]$ & MOD16 & & & SSW, HZI & $\begin{array}{c}\text { Aug, } 27 \text { Aug, and } 3 \\
\text { Sep) }\end{array}$ & $95.3^{\mathrm{r}}$ & $-34.5^{\mathrm{r}}$ & 0.46 \\
\hline $\begin{array}{l}\text { Huang } \\
\text { et al. } \\
\text { [55] }\end{array}$ & SEBS-NDWI & $T_{a}, u, P, R_{d}$ & $\begin{array}{l}T_{r}, \alpha, \varepsilon, \\
\text { NDVI, } \\
\text { NDWI }\end{array}$ & $\begin{array}{l}\text { S1-S17, } \\
\text { GB, SSW, } \\
\text { ZY, HZZ }\end{array}$ & $\begin{array}{c}\text { MODIS (15 Jun to } 5 \\
\text { Sep) }\end{array}$ & 84.1 & 37.6 & \\
\hline & SEBS & $T_{a}, u, P, R_{d}, \mathrm{VP}$ & $T_{r}, \alpha, \varepsilon, \mathrm{NDVI}$ & & & 117.8 & 69.4 & \\
\hline $\begin{array}{l}\text { Ma et al. } \\
{[56]}\end{array}$ & Revised SEBS & $T_{a}, u, P, r_{h}$ & $\begin{array}{c}T_{r}, \alpha, \varepsilon \\
\text { NDVI, LAI }\end{array}$ & $\begin{array}{c}\text { S1-S17, } \\
\text { ZY, GB, } \\
\text { SSW, HZZ }\end{array}$ & $\begin{array}{c}\text { ASTER (15 Jun, } 24 \\
\text { Jun, } 10 \text { Jul, } 2 \text { Aug, } \\
11 \text { Aug, } 18 \text { Aug, } 27 \\
\text { Aug, } 3 \text { Sep, and } 12 \\
\text { Sep) }\end{array}$ & $74.8^{\mathrm{b}}$ & $23^{\mathrm{b}}$ & 0.81 \\
\hline $\begin{array}{l}\text { Zhuang } \\
\text { and Wu } \\
\text { [57] }\end{array}$ & Improved TSEB & $u, T_{a}, r_{h}, P, R_{d}, R_{l d}$ & $T_{r}, \alpha, \varepsilon, \mathrm{NDVI}$ & S6-S14 & $\begin{array}{c}\text { ASTER (11 Aug, } 18 \\
\text { Aug, } 3 \text { Sep, and } 12 \\
\text { Sep) }\end{array}$ & $35.1^{\mathrm{b}}$ & $4.1^{\mathrm{b}}$ & \\
\hline $\begin{array}{l}\text { Song } \\
\text { et al. } \\
{[58]}\end{array}$ & TSEB & $\begin{array}{l}\text { LAI, plant width, } \\
\text { plant height, leaf } \\
\text { width, leaf length, } \\
T_{a}, u, r_{h}, f_{c}, T_{r}\end{array}$ & & $\mathrm{DM}$ & $\begin{array}{c}\text { (18 Jun, } 21 \text { Jun, } 24 \\
\text { Jun, } 10 \text { Jul, } 13 \text { Jul, } \\
18 \text { Aug, } 8 \text { Sep, and } \\
12 \text { Sep) }\end{array}$ & 61 & 31 & \\
\hline $\begin{array}{l}\text { Zhu } \\
\text { et al. } \\
\text { [59] }\end{array}$ & Shuttleworth-Wallace + Bayesian & $\begin{array}{l}\text { LAI, } T_{a}, u, r_{h}, R_{d} \\
R_{l d}, \text { soil moisture }\end{array}$ & & $\mathrm{DM}$ & (26 May to $13 \mathrm{Sep}$ ) & 80.7 & 24.2 & 0.83 \\
\hline
\end{tabular}

Superscripts $b$ and $c$ represent the observed LE corrected via the BR and RE method, respectively. 
TABLE 4: Statistics of the ratios of $\mathrm{LE}_{\text {canopy }}$ to $\mathrm{LE}\left(\mathrm{LE}_{\text {canopy }} / \mathrm{LE}\right)$ and $\mathrm{LE}_{\text {soil }}$ to $\mathrm{LE}\left(\mathrm{LE}_{\text {soil }} / \mathrm{LE}\right), \mathrm{LE}_{\text {canopy }}, \mathrm{LE}_{\text {soil }}$, and $\mathrm{LE}$ modeling accuracies of five dates at the DM station.

\begin{tabular}{|c|c|c|c|c|c|}
\hline Items & Observed average & Estimated average & $\mathrm{MBE}$ & MAE & RMSE \\
\hline $\mathrm{LE}_{\text {canopy }} / \mathrm{LE}(\%)$ & 87.8 & 84.6 & -3.2 & 4.6 & 5.7 \\
\hline $\mathrm{LE}_{\text {soil }} / \mathrm{LE}(\%)$ & 12.2 & 15.4 & 3.2 & 4.6 & 5.7 \\
\hline $\mathrm{LE}_{\text {canopy }}\left(\mathrm{W} \mathrm{m} \mathrm{m}^{-2}\right)$ & 469.3 & 468.4 & -0.9 & 43.9 & 49.3 \\
\hline $\mathrm{LE}_{\text {soil }}\left(\mathrm{W} \mathrm{m} \mathrm{m}^{-2}\right)$ & 63.8 & 85.7 & 21.9 & 25.3 & 33.7 \\
\hline $\mathrm{LE}\left(\mathrm{W} \mathrm{m} \mathrm{m}^{-2}\right)$ & 533.1 & 553.9 & 20.8 & 35.3 & 41.9 \\
\hline
\end{tabular}

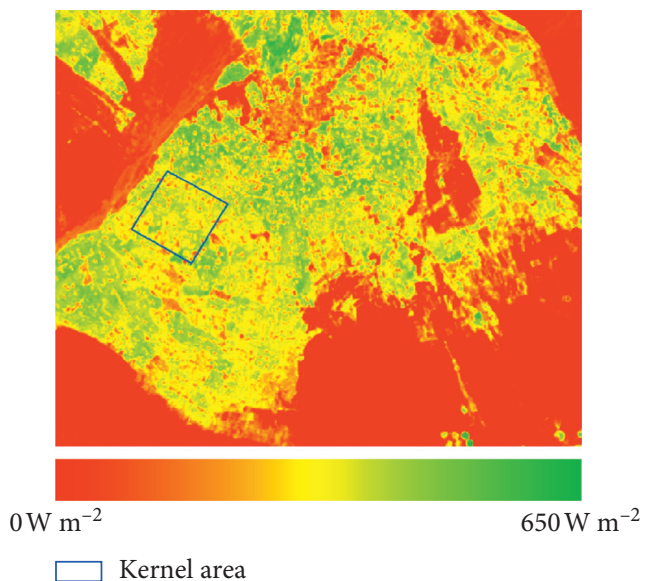

(a)
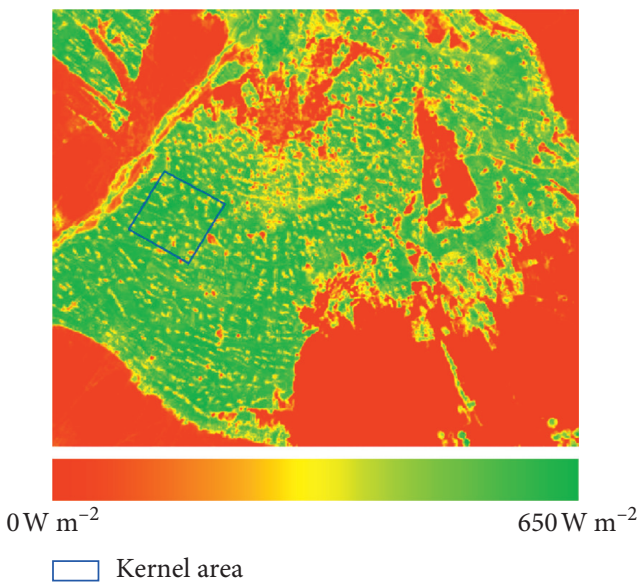

(c)

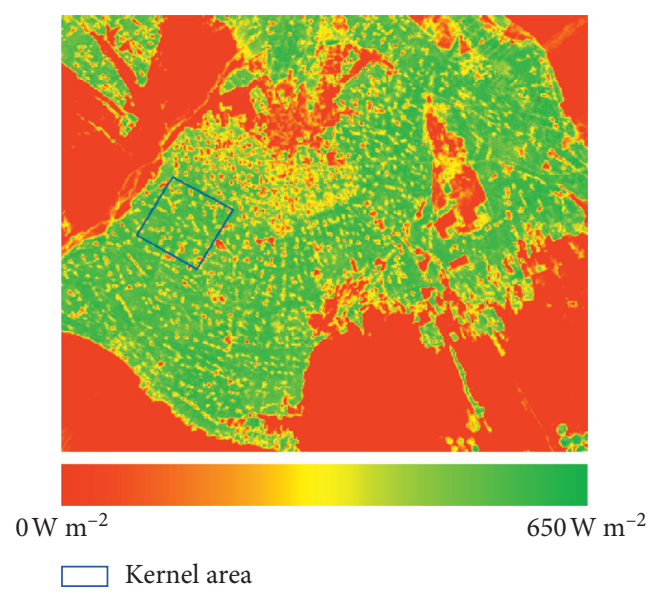

(e)



$0 \mathrm{~W} \mathrm{~m}^{-2}$

$650 \mathrm{~W} \mathrm{~m}^{-2}$

$\square$ Kernel area

(b)
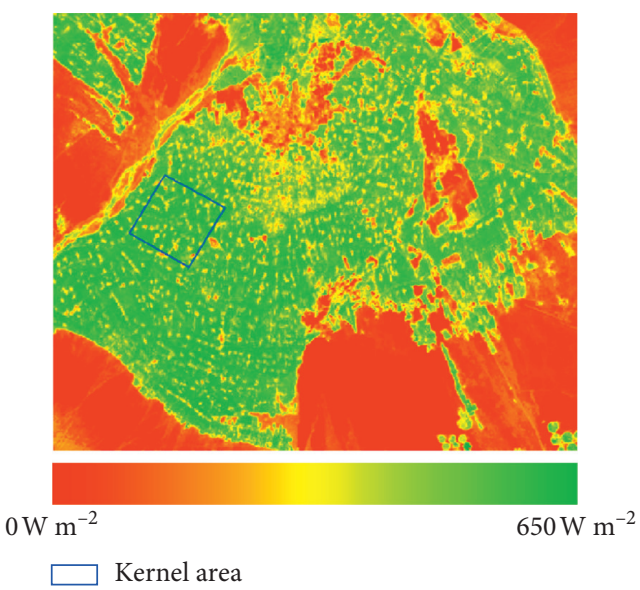

(d)

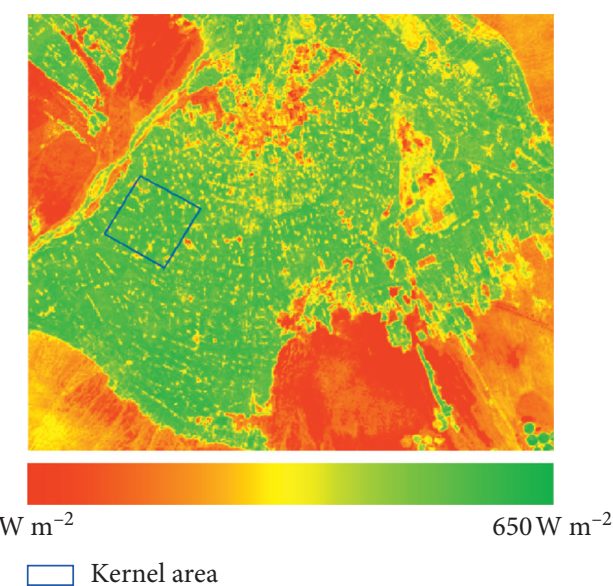

(f)

Figure 5: Continued. 


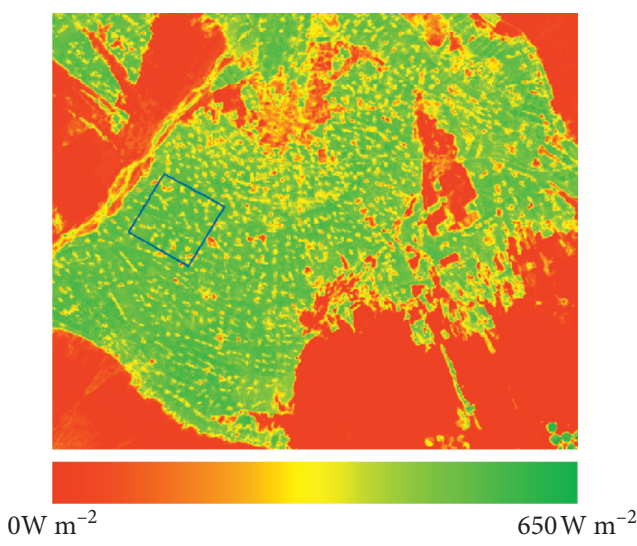

$\square$ Kernel area

(g)

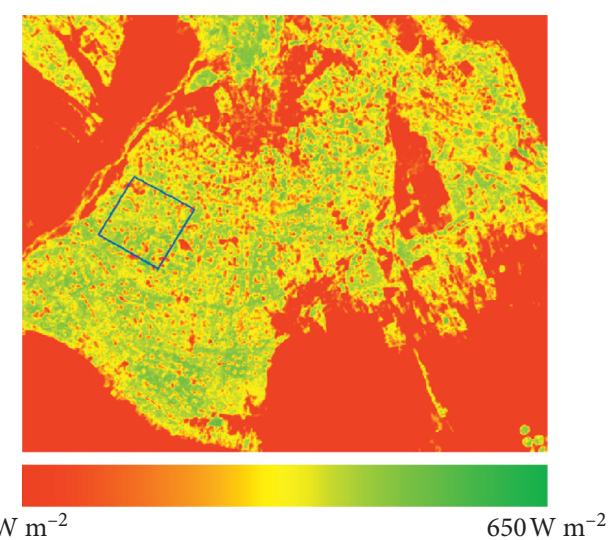

(h)

FIgure 5: Spatial distribution of LE in eight dates ((a) 15 Jun; (b) 24 Jun; (c) 10 Jul; (d) 2 Aug; (e) 11 Aug; (f) 18 Aug; (g) 27 Aug; (h) 3 Sep).
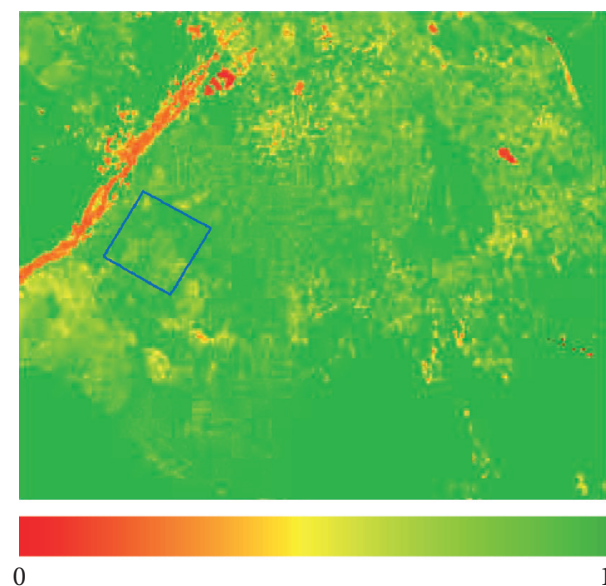

$\square$ Kernel area

(a)
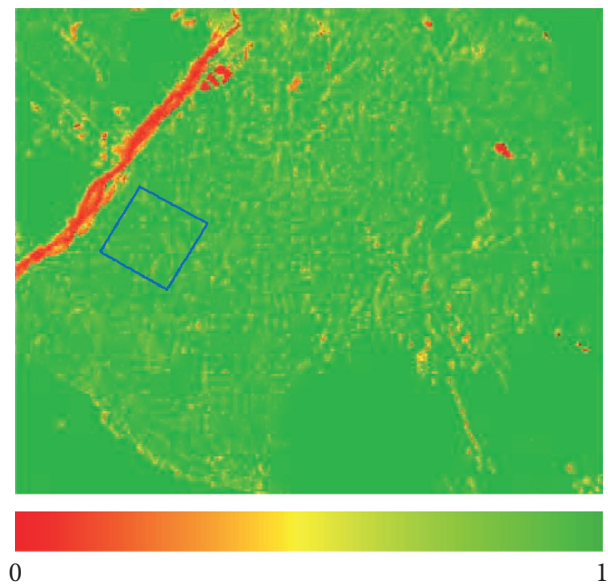

Kernel area
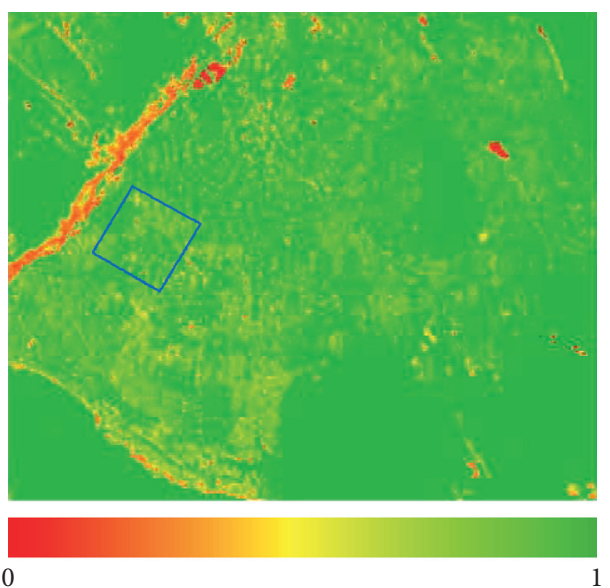

$\square$ Kernel area

(b)
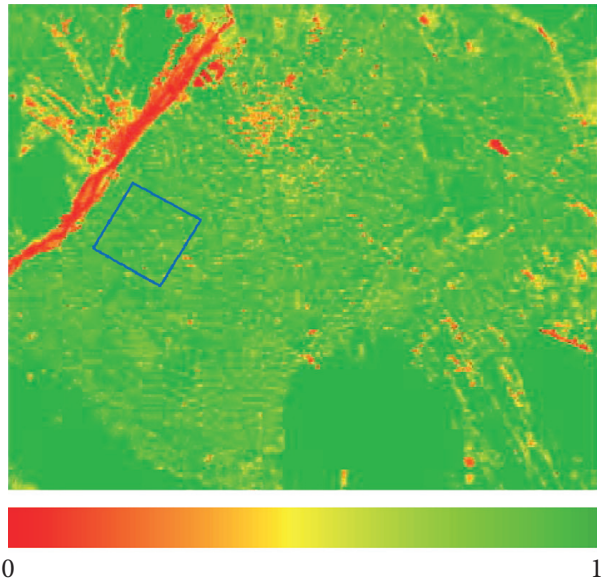

Kernel area

(c)

Figure 6: Continued. 

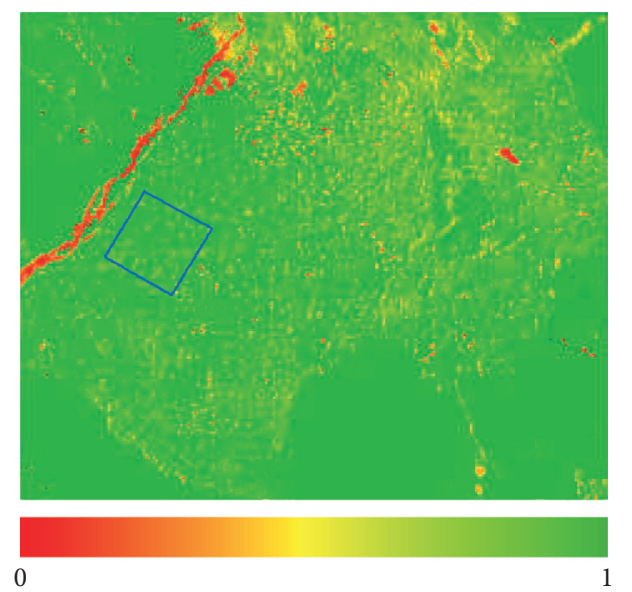

Kernel area

(e)

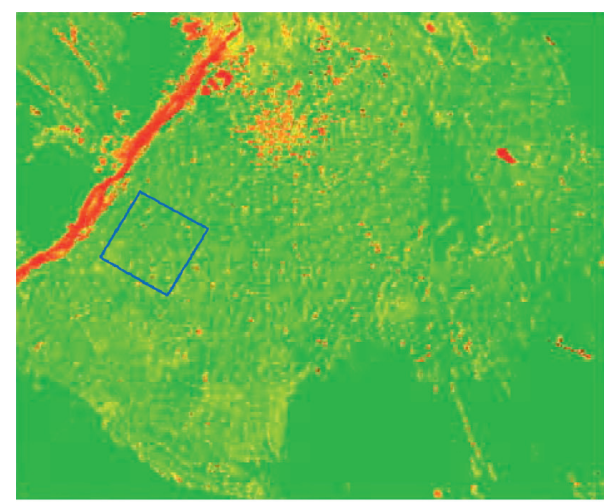

0

Kernel area

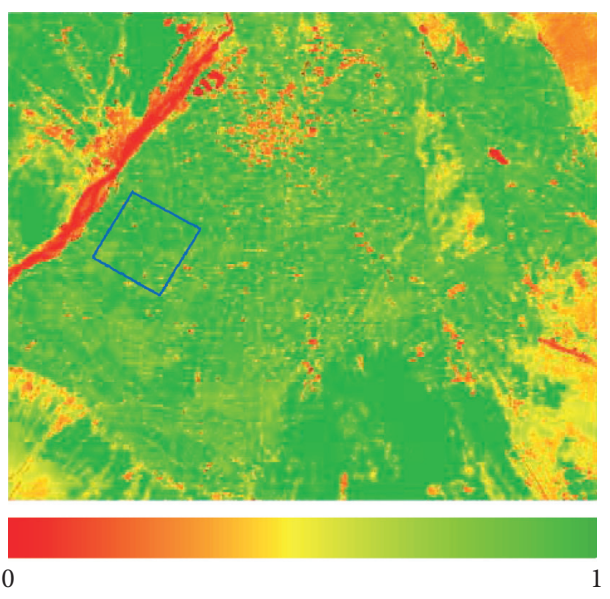

Kernel area

(f)

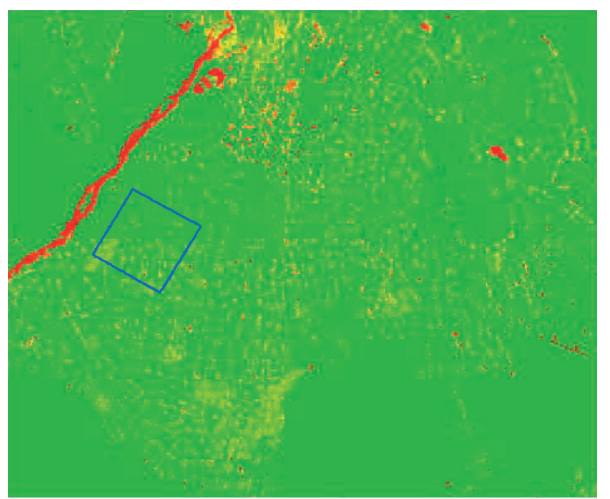

0

Kernel area

$(\mathrm{g})$

(h)

Figure 6: Spatial distribution of $\mathrm{LE}_{\text {canopy }} / \mathrm{LE}$ in eight dates ((a) 15 Jun; (b) 24 Jun; (c) 10 Jul; (d) 2 Aug; (e) 11 Aug; (f) 18 Aug; (g) 27 Aug; (h) 3 Sep).

canopy can use the deep soil water transpiration by maintaining a slight transpiration. $\mathrm{LE}_{\text {canopy }} / \mathrm{LE}$ on the desert and desert steppe surfaces are lower on August 18 than on other dates given soil evaporation increase in relation to precipitation. Crops (including corn and vegetable) and orchard areas have analogous $\mathrm{LE}_{\text {canopy }} / \mathrm{LE}$ with an average of approximately 0.86 . Residential has the lowest $\mathrm{LE}_{\text {canopy }} / \mathrm{LE}$ with an average of 0.72 .

\section{Discussion}

5.1. Sensitivity Analysis. The WiTSEB model inputs include the following details: (1) the ground meteorological observations: $T_{a}, r_{h}$, and $h$; (2) remotely sensed data: $T_{r}, \alpha, \varepsilon$, and EVI; and (3) the parameters: $G_{f 3}, G_{f 4}, \alpha_{1}, \alpha_{2}, \alpha_{3}, \alpha_{4}, z_{0 m c}, r_{c m}$, and $r_{c x}$. Model sensitivity to inputs is analyzed to understand the sources of error and mechanisms of error propagation of the WiTSEB. The sensitivity of LE to the ith input, $S_{i}$, is defined as

$$
S_{i}=\frac{\mathrm{LE}_{ \pm}-\mathrm{LE}_{0}}{\mathrm{LE}_{0}} \times 100 \%,
$$

where $\mathrm{LE}_{0}$ represents the averaged LE estimated by actual inputs, $\mathrm{LE}_{ \pm}$represents the average $\mathrm{LE}$ of eight dates of the study area estimated by the $i$ th input increase $(+)$ or decrease $(-)$ of a value or a ratio with respect to the actual LE, and the variation ranges and steps are $2 \mathrm{~K}$ and $0.5 \mathrm{~K}$ for temperature inputs $\left(T_{a}\right.$ and $T_{r}$ ) and $20 \%$ and $5 \%$ for other inputs, respectively.

In Table 5, the WiTSEB is sensitive to temperature variables. $T_{r}$ and $T_{a}$ are negatively and positively correlated with LE, respectively. A 2 (1) K decrease or increase in $T_{r}$ may result in a $15.9(8.1) \%$ increase or a $17.2(8.5) \%$ decrease in LE estimates, respectively. A perturbation of $-2(-1) \mathrm{K}$ or 2 (1) $\mathrm{K}$ in $T_{a}$ will cause an LE perturbation of $-22.7(-10.8) \%$ or 18.9 (9.9)\%, respectively. The WiTSEB shows a similar magnitude of sensitivity to other remotely sensed variables $\left(\alpha, \varepsilon\right.$, and EVI) and is lower than the sensitivity to $T_{r}$. LE 
Table 5: Sensitivity $S_{i}$ (\%) of LE estimates to each input.

\begin{tabular}{|c|c|c|c|c|c|c|c|c|}
\hline Variations $(\mathrm{K} / \%)$ & $-20(-2)$ & $-15(-1.5)$ & $-10(-1)$ & $-5(-0.5)$ & $5(0.5)$ & $10(1)$ & $15(1.5)$ & $20(2)$ \\
\hline$T_{r}$ & 15.9 & 12.1 & 8.1 & 4.1 & -4.2 & -8.5 & -12.8 & -17.2 \\
\hline$T_{a}$ & -22.7 & -16.6 & -10.8 & -5.3 & 5.1 & 9.9 & 14.5 & 18.9 \\
\hline$\alpha$ & 5.3 & 3.9 & 2.6 & 1.3 & -1.3 & -2.6 & -3.9 & -5.1 \\
\hline$r_{h}$ & 3.7 & 2.9 & 2.0 & 1.0 & -1.1 & -2.4 & -3.7 & -5.2 \\
\hline EVI & -4.5 & -3.2 & -2.0 & -0.9 & 0.8 & 1.3 & 1.7 & 1.9 \\
\hline$\varepsilon$ & 6.2 & 4.6 & 3.0 & 1.5 & -1.5 & -3.0 & -4.4 & -5.8 \\
\hline$G_{f 3}$ & -2.5 & -1.9 & -1.3 & -0.6 & 0.7 & 1.3 & 2.0 & 2.7 \\
\hline$G_{f 4}$ & 2.7 & 2.1 & 1.4 & 0.7 & -0.8 & -1.7 & -2.6 & -3.5 \\
\hline$\alpha_{1}$ & -0.3 & -0.2 & -0.1 & -0.1 & 0.1 & 0.1 & 0.2 & 0.3 \\
\hline$\alpha_{2}$ & 0.1 & 0.0 & 0.0 & 0.0 & 0.0 & 0.0 & 0.0 & -0.1 \\
\hline$\alpha_{3}$ & -1.9 & -1.4 & -1.0 & -0.5 & 0.5 & 1.0 & 1.5 & 2.0 \\
\hline$\alpha_{4}$ & 1.9 & 1.5 & 1.0 & 0.5 & -0.5 & -1.1 & -1.7 & -2.3 \\
\hline$z_{0 m c}$ & -0.6 & -0.4 & -0.3 & -0.1 & 0.1 & 0.3 & 0.4 & 0.5 \\
\hline$h$ & 0.2 & 0.1 & 0.1 & 0.1 & -0.1 & -0.3 & -0.4 & -0.4 \\
\hline$r_{c m}$ & 0.2 & 0.2 & 0.1 & 0.1 & -0.1 & -0.1 & -0.2 & -0.3 \\
\hline$r_{c x}$ & -0.2 & -0.1 & -0.1 & 0.0 & 0.0 & 0.0 & 0.1 & 0.1 \\
\hline
\end{tabular}

Variations of $T_{r}$ and $T_{a}$ in $\mathrm{K}$ and other variables in percentage (\%).

estimates are positive to EVI, and a $20 \%$ increase or decrease in the EVI causes a $1.9 \%$ increase or a $4.5 \%$ decrease in LE estimates, respectively. LE estimates are negative to $\alpha$, $\varepsilon$, and $r_{h}$. A $20 \%$ increase or decrease in $\alpha$ will result in a $5.1 \%$ decrease or a $5.3 \%$ increase. The WiTSEB is insensitive to parameters. The perturbation of LE is less than $3 \%$ when the parameters perturb $20 \%$. LE estimates show a positive relationship with $G_{f 3}, \alpha_{1}, \alpha_{3}, z_{0 m c}$, and $r_{c x}$ but are negatively related to $G_{f 4}, \alpha_{4}, h$, and $r_{c m}$. A -20 (20)\% perturbation of $\alpha_{2}$, $\alpha_{4}$, and $h$ can cause LE perturbations of $0.1(-0.1) \%, 1.9$ $(-2.3) \%$, and $0.2(-0.4) \%$.

Similar sensitivity analyses have been conducted for many trapezoid-based two-source models (Table 6), such as HTEM [10], TTME [13], and ESVEP [33]. In comparison with these models, the WiTSEB avoids using $u$ as the input and does not increase the dependence on other inputs.

Furthermore, if the ground $R_{d}$ and $R_{l d}$ observation is sufficient, we can employ them as inputs to WiTSEB. This way, the performance of WiTSEB could be comparatively improved, i.e., the RMSE of LE decreases from $68.6 \mathrm{~W} \mathrm{~m}^{-2}$ to $62.9 \mathrm{~W} \mathrm{~m}^{-2}$ and the $r^{2}$ increases from 0.88 to 0.89 . We conducted the sensitivity analysis. Both $R_{d}$ and $R_{l d}$ are positive to LE estimates. A $5 \%$ perturbation in $R_{d}$ and $R_{l d}$ may result in $6.6 \%$ and $3.1 \%$ LE estimate variation, which are almost the same as the ESVEP [33] and slightly lower than that of STSEB [11].

\subsection{Error Source Analysis}

5.2.1. Error in $T_{r}$ and $\alpha$ Estimation. The $T_{r}$ observation is computed as

$$
T_{r}=\left(\frac{R_{l u}-(1-\varepsilon) R_{l d}}{\varepsilon \sigma}\right)^{1 / 4}
$$

where $R_{l u}$ and $R_{l d}$ are the observed upward and downward longwave radiation $\left(\mathrm{W} \mathrm{m}^{-2}\right)$, respectively. Land surface emissivity $\varepsilon$ is derived from the $T_{r}$ product, which is estimated by the TES algorithm.
In Figure $7(\mathrm{a})$, the $T_{r}$ product shows consistency with the observation, with MBE, MAE, RMSE, and $r^{2}$ of $1.1 \mathrm{~K}$, $2.0 \mathrm{~K}, 2.9 \mathrm{~K}$, and 0.89 , respectively. The $T_{r}$ product shows high accuracy at the corn and orchard area. Similarly, LE estimates at both areas yield a high accuracy (Figure 4(d) and Table 1). $T_{r}$ is overestimated in the Gobi, desert steppe, and desert areas, with an MBE of 2.1, 4.6, and $5.4 \mathrm{~K}$, respectively. LE estimates at the sparse vegetation areas are negatively biased by $42.1,108.3$, and $73.9 \mathrm{~W} \mathrm{~m}^{-2}$, respectively. On June 15, June 24, August 2, August 11, August 27, and September 3, $T_{r}$ at the desert steppe site is overestimated by $4.5,4.6,6.0,3.4,5.6$, and $5.6 \mathrm{~K}$, respectively, thus potentially rendering the point $\left(f_{c}, T_{r}\right)$ out of the envelope displayed in Figure 1(b) and resulting in LE estimates at approximately 0 . At the residential site, $T_{r}$ is significantly underestimated, which is consistent with an LE overestimation of $34.9 \mathrm{~W} \mathrm{~m}^{-2}$ presented in Figure 4(d) and Table 1.

Similar to $T_{r}, \alpha$ is also estimated from the ASTER image. The estimated $\alpha$ has an RMSE of 0.021 and an $r^{2}$ of 0.65 . $\alpha$ shows slight overestimation in general compared with the observation from AWS (Figure 7(b)) with an MBE of 0.01. However, $\alpha$ gives significantly underestimated over wetland, with an $\mathrm{MBE}$ of -0.05 , which creates the comparatively overestimations of $R_{n}$ (Figure 4(a) and Table 1) and LE (i.e., an MBE of $70.7 \mathrm{~W} \mathrm{~m}^{-2}$ ) even though $T_{r}$ is overestimated (i.e., an $\mathrm{MBE}$ of $0.64 \mathrm{~K})$.

5.2.2. Error in $T_{a}$ Interpolation. We calculate the standard deviations (SD) of grids in the $90 \mathrm{~m} \times 90 \mathrm{~m}$ resolution to quantify a spatial variability (Table 7) and employ the leaveone-out crossvalidation (LOOCV) method to analyze interpolation accuracy (Figure 8 ). The SD varies between $0.1 \mathrm{~K}$ and $0.3 \mathrm{~K}$ with an average of $0.2 \mathrm{~K}$ in eight dates, thereby indicating low spatial variability. The interpolated $T_{a}$ shows a favorable relationship with the observation given the $r^{2}$ of 0.97. The interpolated $T_{a}$ is lower than the observation $T_{a}$ of $0.2 \mathrm{~K}$ and has an MAE and RMSE of $0.4 \mathrm{~K}$ and $0.5 \mathrm{~K}$, 
TABLe 6: Sensitivity $S_{i}$ (\%) of LE estimates to each input in other two-source models based on trapezoidal space.

\begin{tabular}{|c|c|c|c|c|c|c|c|c|c|c|c|c|}
\hline \multirow{2}{*}{ Models } & \multicolumn{2}{|c|}{$T_{r}(\mathrm{~K})$} & \multicolumn{2}{|c|}{$T_{a}(\mathrm{~K})$} & \multicolumn{2}{|c|}{$\alpha$} & \multicolumn{2}{|c|}{$\alpha_{2}$} & \multicolumn{2}{|c|}{$\alpha_{4}$} & \multicolumn{2}{|c|}{$h$} \\
\hline & $-2(-1)$ & $2(1)$ & $-2(-1)$ & $2(1)$ & $-20 \%$ & $20 \%$ & $-20 \%$ & $20 \%$ & $-20 \%$ & $20 \%$ & $-20 \%$ & $20 \%$ \\
\hline TTME & $28.9(14.4)$ & $-28.6(-14.3)$ & $-27.7(-13.9)$ & $27.6(23.8)$ & & & 1.4 & -1.4 & 4.9 & -5.7 & 1.5 & -1.5 \\
\hline HTEM & $17.3(9.5)$ & $-23.2(-11)$ & $-21(-10)$ & $15.3(8.5)$ & 7.1 & -7.0 & 0.73 & -0.75 & 2.02 & -2.04 & 2.4 & -2.1 \\
\hline ESVEP & $(6.5)$ & $(-7.7)$ & $(-6.9)$ & (5.7) & 4.7 & -5.0 & & & & & -0.5 & 0.5 \\
\hline
\end{tabular}

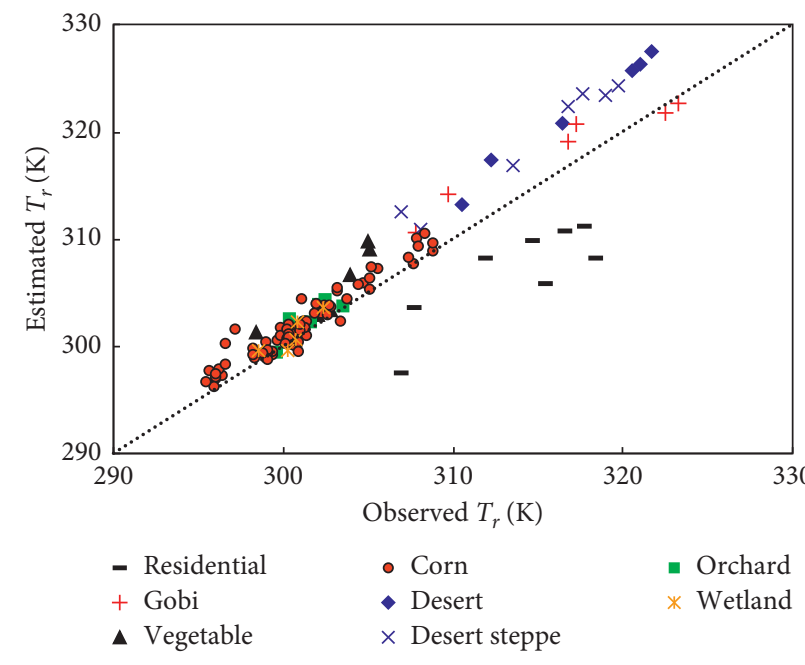

(a)

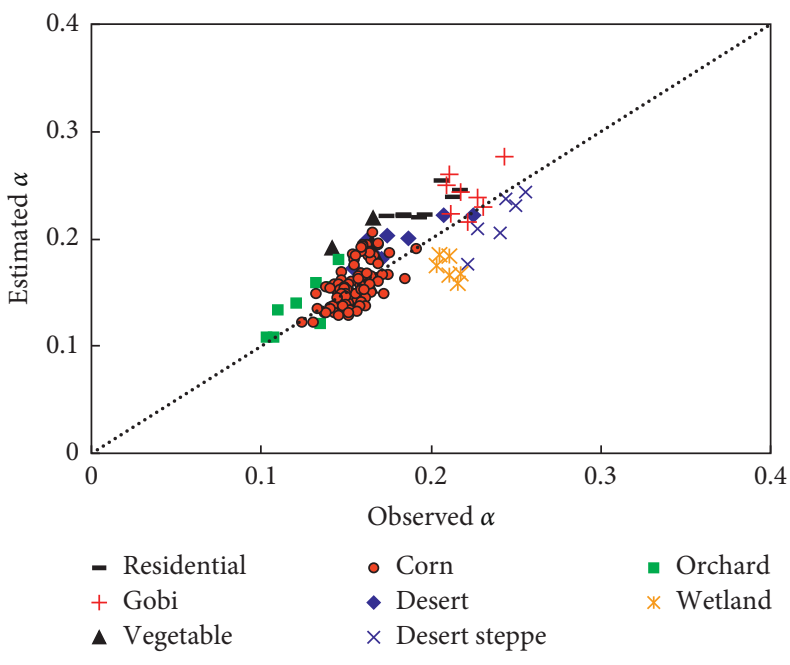

(b)

Figure 7: Comparison of the observation and the estimation for different land covers: (a) $T_{r}$ and (b) $\alpha$.

TABle 7: Minimum (min), maximum (max), mean, and standard deviations (SD) of grids $T_{a} \mathrm{~K}$ interpolated via the IDW method with a $90 \mathrm{~m} \times 90 \mathrm{~m}$ resolution of the study area over eight dates.

\begin{tabular}{lcccc}
\hline Dates & Min & Max & Mean & SD \\
\hline 15 Jun & 297.7 & 299.0 & 298.4 & 0.1 \\
24 Jun & 297.8 & 300.2 & 299.1 & 0.3 \\
10 Jul & 299.1 & 300.9 & 300.0 & 0.1 \\
2 Aug & 300.5 & 302.8 & 301.8 & 0.3 \\
11 Aug & 297.9 & 299.2 & 298.6 & 0.1 \\
18 Aug & 296.3 & 297.5 & 297.0 & 0.2 \\
27 Aug & 298.6 & 300.7 & 299.8 & 0.3 \\
3 Sep & 291.4 & 293.0 & 292.3 & 0.2 \\
\hline
\end{tabular}

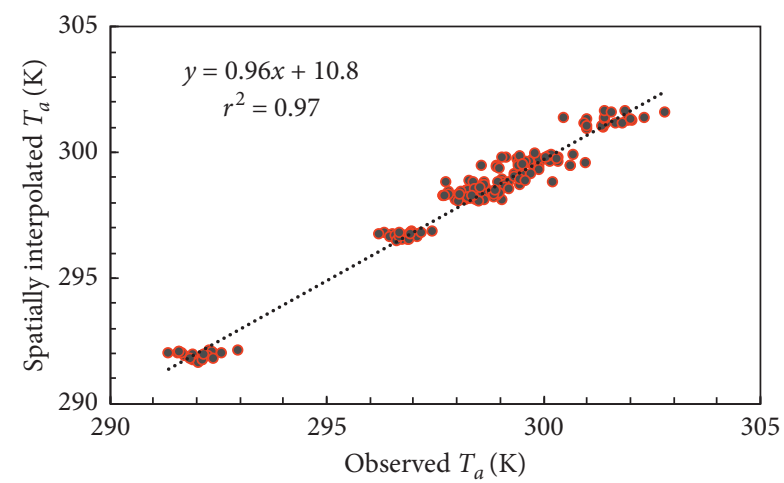

FIGURE 8: Observed $T_{a}$ vs. estimated $T_{a}$ via the LOOCV method in the study area over eight dates. respectively. Those two indices imply that $T_{a}$ may not be the main error source of the WiTSEB model in this study area.

However, researchers need to be cautious when to use the method to complex topography and rare stations area because the performance of the interpolation methods is sensitive to the density and variability of meteorological data. Webster et al. [25] evaluated seven interpolation methods at a diverse topography and high landscape heterogeneity area in Southeastern Australia and found that no single spatial interpolation method can provide a reliable performance across various conditions and meteorological data.

5.2.3. Errors Introduced by the Assumption. To circumvent the dependence on $u$, an assumption, i.e., the water-saturated surface is under neutral conditions, is used to construct the $T_{r}-f_{c}$ trapezoid (Figure 1(b)) and to calculate the LE components by means of averaged $T_{a}$ of vegetable, corn, and wetland landscapes. Using a certain condition of $T_{a}$ as $T_{c, \text { min }}$ and $T_{s, \text { min }}$ is a common practice for constructing a theoretical $T_{r}$-VI or $T_{r}-f_{c}$ trapezoidal space $[10,13,27,32]$. Tang and $\mathrm{Li}$ [33] found that the estimated $T_{c, \text { min }}$ and $T_{s, \text { min }}$ via Moran's method [60] were slightly different from the $T_{a}$ at the Yucheng station covered by croplands over the 58 clearsky days from March 2010 to October 2011. Wang et al. [4] found that the calculated $T_{c \text {,min }}$ via a revised Moran's method is lower than the pixel $T_{a}$ of $2.9 \mathrm{~K}$, However, the discrepancy is related to the semiarid spare vegetation condition. Nevertheless, Prince and Goward [61] believed that the 
magnitude of the difference between the two temperatures is approximately $2 \mathrm{~K}$.

Here, we analyze error propagation in the WiTSEB variables (i.e., $R_{n c 1}, R_{n s 3}, r_{a s 0}, r_{a c 0}, r_{a s}, r_{a c}, T_{s, \max }, T_{c, \max }, T_{s}, T_{c}$, $H_{c}, H_{s}, H$, and LE) by introducing the decrease in $T_{c, \min }$, $T_{s \text {,min }}$, and both at $3 \mathrm{~K}$ by considering the research of Wang et al. [4]. In Figure 9, a $3 \mathrm{~K}$ decrease in $T_{s, \min }$ causes the magnitude of increase or decrease in variables less than $4.5 \%$, where the magnitudes are 0 in the $R_{n c 1}, r_{a c 0}, r_{a c}$, and $T_{c, \max }$ estimate. A $3 \mathrm{~K}$ decrease in $T_{c, \min }$ and in $T_{c, \min }$ and $T_{s, \min }$ results in an increase in $H_{c}$ estimates of $15.1 \%$ and $16.3 \%$, respectively, whereas the effects on other variables are not obvious with $5.5 \%$ and $6.9 \%$ in $H$ estimates and $-3.3 \%$ and $-4.3 \%$ in LE estimates, respectively.

5.3. Uncertainty in G. EC flux measurements are extensively known as an energy imbalance, i.e., the sum of the observed fluxes $(H+\mathrm{LE})$ is less than the available energy $\left(R_{n}-G\right)$, thereby yielding an approximately $16 \%$ uncertainty for LE during HiWATER-MUSOEXE-12 [62]. Reasons that cause energy unclosure include mismatch of measurement footprints [63], horizontal advection, and ignoring heat storage in measuring $G$ [64]. Here, we emphatically analyze the $G$ measurement error and its effect on the LE observation. The Plate Cal method [45] is used to observe G. Sites (including S4 residential, HZZ desert steppe, and ZY wetland) are not used in calculating the heat storage changes given a lack of soil porosity measurements, thus resulting in the $G$ observations less than the actual value. Consequently, the corrected $L E$ via the $B R$ method will be higher than the actual value. The $\mathrm{HZZ}$ desert steppe has a less systemic error of $T_{r}$ estimate (MBE of $4.6 \mathrm{~K}$ vs. $5.4 \mathrm{~K}$ ) but has a larger LE underestimation $\left(-108.3 \mathrm{~W} \mathrm{~m}^{-2}\right.$ vs. $\left.-73.9 \mathrm{~W} \mathrm{~m}^{-2}\right)$ than the desert site. This contrast can be interpreted by the observed error of LE caused by $G$ observation, i.e., the underobserved $G$ augments the BR-corrected LE and aggravates the underestimation of LE estimates. Furthermore, the underobserved $G$ at the residual site mitigates the overestimation caused by the significant underestimation of $T_{r}$.

The result shown in Figure 4(b) and Table 1 indicates a relatively large disagreement between the estimated $G$ and the measured $G$. This disagreement is likely due to the fixed value of $C_{G}$ throughout the study area across all the eight days. $C_{G}$ was reported to vary with time of day, soil type, and soil moisture [36]. Specifically, $C_{G}$ shows diurnal variation [65] but normally is constant at the time range around local solar noon [66] and the ASTER overpass time is within the time range; therefore, the strategy of set $C_{G}$ as constant in the given soil type and soil moisture condition on a day is acceptable. There has been a systematically overestimated $G$ at Gobi and desert sites, which contrasts to the performance in the vegetable site. This discrepancy can be explained by soil properties difference [54], i.e., the dry rock and sandy soil has lower soil heat capacity than vegetable soil due to the lower soil moisture and higher soil porosity [67]. As to the effect of soil moisture on $C_{G}$, it is hard to quantitatively evaluate in this study because we lack ground data to isolate the effects of soil properties over corn which is the only landscape showing statistical significance. Importantly, local calibration of $C_{G}$ for the sites of the study area would improve the agreement; however, the purpose of this study is to build a broadly applicated $u$-independent two-source energy balance model rather than to tune it to those specific sites.

5.4. Comparison of $T_{r}$ Decomposition Methods. The decomposition of $T_{r}$ into $T_{c}$ and $T_{s}$ is a key process for twosource models. Four direct methods, namely, multiangle method [68], empirical method [69], wetness isoline method [70], and two-stage ET method [32, 33], are adopted; furthermore, one indirect method, namely, the Priestley-Taylor iteration method [9], is used. Given a lack of two-view angle images, here, except for the multiangle method, we mainly discuss three direct methods, i.e., the empirical, wetness isoline, and two-stage ET methods.

The empirical method uses the empirical relationship between $T_{s}-T_{c}$ and $T_{r}-T_{a}$ (i.e., $T_{s}-T_{c}=C_{a}\left(T_{r}-T_{a}\right)^{m}$, where $C_{a}=0.1$ and $m=2$ ) [69] to segment $T_{r}$. We drew the relationship between $T_{c}$ and $T_{r}$ under a given meteorological condition $\left(T_{a}=293 \mathrm{~K}\right)$ based on the Lhomme relationship. In Figure 10, $T_{c}$ increases approximately linearly with $T_{r}$ in the high vegetation cover $\left(f_{c}>0.7\right)$ area, whereas $T_{c}$ decreases with the increase in $T_{r}$ under the $f_{c}<0.7$ condition. This phenomenon is opposite to the natural state, in which $T_{r}$ and $T_{c}$ increase with water stress and vegetation transpiration constraint. Furthermore, $T_{c}$ is even smaller than 0 under the condition of $T_{r}>315 \mathrm{~K}$ (i.e., $T_{r}-T_{a}>20 \mathrm{~K}$ ) in sparse areas. In fact, an average $T_{r}-T_{a}$ in eight dates on the ASTER overpass time at the desert, desert steppe, and Gobi areas is 20.9, 18.2, and $18.1 \mathrm{~K}$, respectively. Thus, $T_{c}$ in those areas is erroneously estimated. These phenomena verify the limitation of empirical relationships, especially at sparse areas [71]. Moreover, Lhomme empirical coefficients vary with regions. Zhan et al. [71] reported that the coefficient $C_{a}$ fluctuates between 0.07 and 0.27 when $m$ is set to 2 based on the measured data from FIFE'87, Monsoon'90, and Washita'92 sites.

The wetness isoline method was originally proposed in the PCACA model [70] with the assumption of a nearly straight isopiestic wetness line with equivalent $T_{s}$ and $T_{c}$ under a uniform atmospheric environment and homogeneous soil surface. This method has similarity with the twostage ET method in using a trapezoidal space to segment $T_{r}$. However, the decomposed component temperatures between the two methods are considerably different. Here, the $T_{c}$ and $T_{s}$ decomposed from the wetness isoline method denote the $T_{r}-f_{c}$ trapezoidal space as $T_{c \text {,Zhang }}$ and $T_{s \text {,Zhang }}$ to make a distinction. In Figure $11, T_{c}$ is nearly equal to $T_{a}$ with an average of $297.9 \mathrm{~K}$ in eight dates at the DM station. By contrast, $T_{c \text {,Zhang }}$ is larger than $T_{c}$ by $3.5 \mathrm{~K}$. Carlson [41] asserted that $T_{c}$ is primarily driven by the soil moisture in the root zone. Wu et al. [72] reported that the depth of the corn root zone is $20-80 \mathrm{~cm}$ in the growing period. Here, we calculated the soil moisture in the root zone by the average soil moisture of 20,40 , and $80 \mathrm{~cm}$ and found the soil moisture in the corn root zone is slightly greater than the field capacity in all dates, thereby indicating that the 




FIgURE 9: Relative changes in variables in the WiTSEB with the decrease in $T_{s, \min }$ or $T_{c, \text { min }}$ by $3 \mathrm{~K}$.

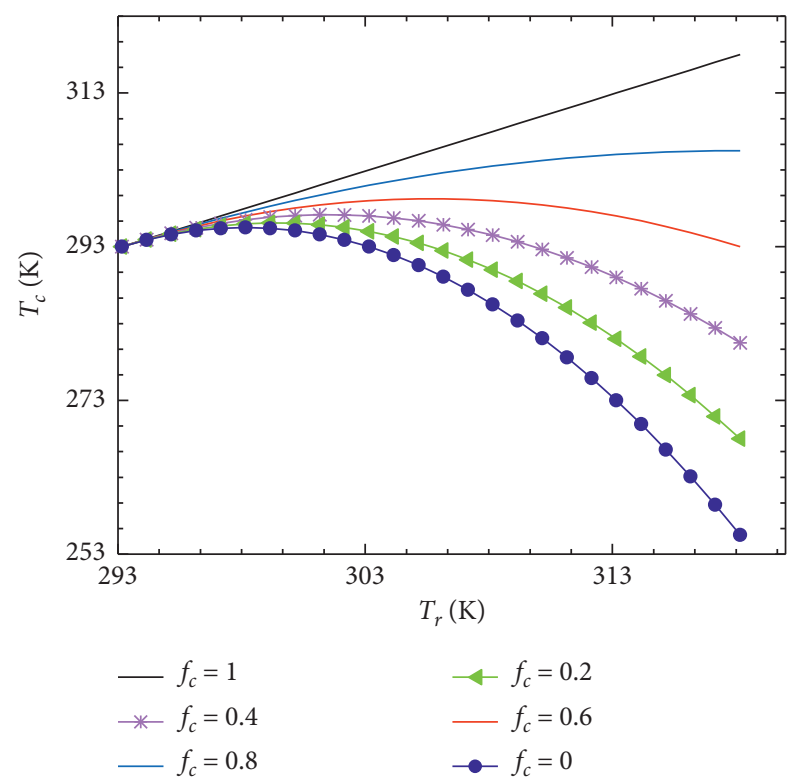

FIgURE 10: $T_{c}$ variables with $T_{r}-T_{a}$ under different $f_{c}$ conditions in Lhomme empirical relationship.

vegetation transpiration is not stressed. Therefore, $T_{c}$ in theory is approximately equal to $T_{a}$. The average of $T_{s}$ is $307.7 \mathrm{~K}$ and is clearly higher than $T_{s \text {,Zhang }}$ of $5.6 \mathrm{~K} . T_{s}$ is driven primarily by the soil surface moisture $(\sim 2 \mathrm{~cm})$ by considering that $T_{r}$ in actual is "skin temperature" at depths in which electromagnetic radiation at the given wavelengths can penetrate [73].

Moreover, the significant differences are also embodied in $T_{s}-T_{c}$. The average of $T_{s}-T_{c}$ in eight dates is $9.7 \mathrm{~K}$, and the $T_{s, \text { Zhang }}-T_{c \text {, Zhang }}$ is only $0.8 \mathrm{~K}$. On June 24 , significant water stress occurred with the moisture of soil surface only $10.5 \% . T_{s}$ in theory must be clearly larger than $T_{c}$; however, the $T_{s, \text { Zhang }}-T_{c \text {, Zhang }}$ is only $2.2 \mathrm{~K}$ (Figure 11 ), which may be relatively small compared to observations. Previous studies have reported that the observed $T_{s}-T_{c}$ may exceed $10 \mathrm{~K}$. For example, Colaizzi et al. [74] found that $T_{s}-T_{c}$ is over $10 \mathrm{~K}$ at noon in the early- and midseason at the upland cotton area, Bushland, Texas, USA, in accordance with the observations from IRT (model IRT/c,
Exergen Corp., Watertown, Massachusetts, USA). Tian et al. [75] reported that soybeans $T_{s}-T_{c}$ has an extremum of more than $20 \mathrm{~K}$ at noon by using a thermal infrared imager (Fluke IR FlexCam Ti55, Fluke Crop., USA). Some researchers observed the $T_{s}-T_{c}$ often exceeding $20 \mathrm{~K}$ in semiarid environments (e.g., Chehbouni et al. [76], Humes et al. [77], and Kustas et al. [78]). Kustas and Norman [22] emphasized that the average $T_{s}-T_{c}$ has an extreme of $25 \mathrm{~K}$ in cases. Allen et al. [79] indicated that $T_{s}-T_{c}$ can be $20-30 \mathrm{~K}$ at the exposed and dry surface.

The ET methods is based on the wetness isoline estimate soil evaporation fraction $\left(\left(\mathrm{LE}_{s} /\left(R_{n s}-G_{s}\right)\right)\right.$ and vegetation transpiration fraction $\left(\mathrm{LE}_{c} / R_{n c}\right)$ with the assumption that they vary quasilinear with $T_{s}$ and $T_{c}$ in the trapezoid space, respectively; these methods include PCACA [70], TTME [13], and estimated potential evaporation fraction $\left(\mathrm{LE}_{s} / \mathrm{LE}_{s p}\right.$, $\mathrm{LE}_{s p}$ is the potential evaporation of soil surface) and vegetation potential transpiration fraction $\left(\mathrm{LE}_{c} / \mathrm{LE}_{c p}\right)$ which are quasilinear with $T_{s}$ and $T_{c}$, respectively, (e.g., ETEML (Yang et al. [80]). Based on our assumption, we could deduce the rough equality between evaporation and transpiration fractions [33] and the equality between the soil and vegetation potential evaporation ratios. Here, we calculated the potential evaporation and transpiration fractions using the observed $\mathrm{LE}_{\text {soil }} / \mathrm{LE}, \mathrm{LE}$, and meteorological data (i.e., $T_{a}, r_{h}$, and $u$ ) at the DM station to assess the deduction, in which the observed $\mathrm{LE}_{s}$ is calculated by $\mathrm{LE}_{\text {soil }} / \mathrm{LE} \times \mathrm{LE} /\left(1-f_{c}\right) ; f_{c}$ is calculated via the method proposed by Anderson et al. [81], in which the $\mathrm{LE}_{s p}$ and $\mathrm{LE}_{c P}$ are calculated using the equations recommended by $\mathrm{Mu}$ et al. [8] and Guan and Wilson [82]:

$$
\begin{aligned}
& \mathrm{LE}_{s p}=\frac{\Delta\left(R_{n s}-G\right)}{\Delta+\gamma\left(r_{t o t} / r_{s}\right)}+\frac{\rho C_{p} \mathrm{VPD} / r_{s}}{\Delta+\gamma\left(r_{\text {tot }} / r_{s}\right)}, \\
& \mathrm{LE}_{c p}=\frac{\Delta R_{n c}}{\Delta+\gamma\left(r_{s, \text { min }} / r_{a}\right)}+\frac{\rho C_{p} \mathrm{VPD} / r_{a}}{\Delta+\gamma\left(r_{s, \text { min }} / r_{a}\right)},
\end{aligned}
$$

where $r_{s}, r_{a}$, and $r_{\text {tot }}$ are the aerodynamic resistances of the soil surface, canopy surface, and the total, respectively, and $r_{s, \text { min }}$ is the minimum surface resistance.

In Figure 12, the potential evaporation fraction is obviously lower and fluctuates more dramatically than the potential transpiration fraction. The potential evaporation 




Figure 11: Estimated $T_{\mathrm{c}}$ and $T_{\mathrm{s}}$ from the soil wetness isoline and the two-stage ET with observed two-layer soil moisture at the DM station; the soil moisture in the root zone is the average of 20,40 , and $80 \mathrm{~cm}$ based on the research of Wu et al. [72].



Figure 12: Potential evaporation and transpiration changes with observed multilayer soil moisture at the DM station. The three down arrows indicate three flood irrigations.

fraction ranges between 0.09 and 1.32 , with an average and a standard deviation of 0.47 and 0.24 , respectively. Notably, the potential evaporation fraction greater than 1 on July 30 is mainly due to a small $E_{s P}$ that resulted from a high $r_{h}$ value $(79 \%)$. The potential transpiration fraction fluctuates between 0.81 and 1.37, with an average and a standard deviation of 0.95 and 0.1 , respectively. Moreover, the potential transpiration fraction at the grain filling period (roughly before August) has an average of 0.98, which is higher than that at the mature period (roughly August and later), at 0.91. Therefore, the wetness isoline method potentially overestimates $\mathrm{LE}_{\text {soil }}$ and underestimates $\mathrm{LE}_{\text {canopy }}$. The MBE of $\mathrm{LE}_{\text {soil }}$ and $\mathrm{LE}_{\text {canopy }}$ via the wetness isoline method is 53.4

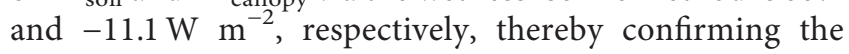
conclusion.

Two preconditions are implied in the two-stage ET method. The first precondition is that the soil moisture decreases at the root zone lag behind that on the surface $(\sim 2 \mathrm{~cm})$. The second precondition is that the soil moisture variation is the driver of radiative temperature and ET changes. Figure 12 illustrates that surface soil moisture shows a dramatic decrease in the intervals between two instances of flood irrigation (DM exhibited flood irrigation on July 2, July 28, and August 28 [44]). The soil moisture in the root zone decreases during the intervals and is maintained in a scope that is greater than the field capacity, thus indicating no water stress. $T_{c}$ has been recognized and used extensively as an indicator of water availability such as the calculation of the crop water stress index (CWSI) [83]. Moran et al. [60] developed the concept of CWSI to bare soil and proposed the water deficit index, indicating that $T_{s}$ is approximately linearly related to surface soil moisture and soil evaporation under a given $T_{a}, R_{n}, \mathrm{VPD}$, and $r_{a}$, as verified by Vidal and Perrier [84]. Therefore, applying the two-stage ET method is appropriate for segmenting $T_{r}$ under a given meteorological condition.

\section{Conclusions}

The reduction in the dependence on the ground meteorological data, especially the data known as high spatial and temporal variation, i.e., wind speed $u$, is significant for mitigating uncertainties of remotely sensed ET in large-scale and heterogeneous surfaces. In this study, we propose a WiTSEB model by using a simplified theoretical surface temperature $\left(T_{r}\right)$-vegetation coverage $\left(f_{c}\right)$ trapezoid, a two- 
stage ET $T_{r}$ decomposing method, and the two-source patch framework.

The WiTSEB was conducted in HiWATER-MUSOEXE12 sites at the desert-oasis transition zone of Zhangye City in the middle reaches of the Heihe watershed using ASTER images over eight dates. $R_{n}, H$, and LE estimates agree well with the observations from 21 flux towers. The RMSE and $r^{2}$ of LE estimates are $68.6 \mathrm{~W} \mathrm{~m}^{-2}$ and 0.88 , respectively. The accuracies of $R_{n}, G, H$, and LE estimates significantly vary with land cover types (including corn, desert, Gobi, desert steppe, orchard, vegetable, residential, and wetland). The MBE and RMSE of $\mathrm{LE}_{\text {canopy }} / \mathrm{LE}$ estimates are $-3.2 \%$ and $5.7 \%$, respectively, in comparison with the CRDS water vapor isotope measurement. The LE estimate shows a high spatial variation across landscapes. The LE estimate is generally large in high vegetation cover areas and low in sparse vegetation areas. Furthermore, irrigation strategy amplifies spatial difference. The LE estimates at cropland (corn and vegetable) are high in July and August and low in June and September. The LE estimates at the orchard and wetland areas show less temporal variation between June and August but are conspicuously larger than the value in September. Precipitation is the primary reason for the LE temporal variation at low vegetation cover areas.

The WiTSEB is most sensitive to $T_{a}$ and $T_{s}$ but insensitive to other meteorological, remote sensing, and other parameters. A $2 \mathrm{~K}$ increase in $T_{r}$ and $T_{a}$ results in a $17.2 \%$ decrease and a $18.9 \%$ increase in LE estimates, respectively. A $20 \%$ perturbation of other inputs causes a sensitivity that reaches $6.2 \%$. In comparison with the other two-source models, the WiTSEB does not aggravate the sensitivity on meteorological and remote sensing inputs. Error analysis shows that the estimate error of $T_{r}$ contributes to the LE overestimation/underestimation at certain land cover types. The observed error of $G$ can exacerbate LE underestimation and mitigate LE overestimation. Rationality assessment indicates that the assumption, which is employed to avoid $u$ in constructing a $T_{r}-f_{c}$ trapezoidal space and iteratively calculating $H$ components, yields minimal influence on core variable estimates.

The rationality of a two-stage ET pattern in decomposing $T_{r}$ is comprehensively verified by using the ground meteorological observations in the DM station. Compared to the empirical and wetness isoline, the two-stage ET pattern provides more flexibility to the natural environment and gives higher accuracy in LE estimation.

As with other satellite-based models, WiTSEB has a certain limitation because of some not routinely available inputs, such as the canopy height $(h)$ [1], which is one of necessary factors on simulation of surface roughness and aerodynamic resistance. The uncertainty of the parameterization (i.e., $r_{c x}, r_{c m}, G_{f}$, and $\alpha$ ) under extreme conditions for constructing the $T_{r}-f_{c}$ trapezoidal space also needs to be worked on further.

\section{Data Availability}

The ground observed data used to support the findings of this study are released upon application to the Cold and Arid
Regions Science Data Center at Lanzhou (http://card. westgis.ac.cn/). The L1B ASTER image is freely downloadable at US Geological Survey website (https:// earthexplorer.usgs.gov/). The remotely sensed products, including albedo and enhanced vegetation index, are available from the corresponding author upon request.

\section{Conflicts of Interest}

The authors declare that they have no conflicts of interest.

\section{Acknowledgments}

The authors thank the Heihe Plan Science Data Center, National Natural Science Foundation of China, for providing ground and near-surface measurements obtained in the Heihe Watershed Allied Telemetry Experimental Research (HiWATER, http://westdc.westgis.ac.cn/hiwater). This work was supported by the China National Key Research and Development Program (grant no. 2017YFC0405801-02), the Technologic Innovation Foundation of Pearl River Hydraulic Research Institute (grant no. [2018] ky015), CRSRI Open Research Program (no. CKWV2017529/KY), Fundamental Research Funds for the Central Universities (no. 2017B614X14), and Postgraduate Research \& Practice Innovation Program of Jiangsu Province (no. KYCX17_0419).

\section{References}

[1] Z.-L. Li, R. Tang, Z. Wan et al., "A review of current methodologies for regional evapotranspiration estimation from remotely sensed data," Sensors, vol. 9, no. 5, pp. 3801-3853, 2009.

[2] J. D. Kalma, T. R. Mcvicar, and M. F. Mccabe, "Estimating land surface evaporation: a review of methods using remotely sensed surface temperature data," Surveys in Geophysics, vol. 29, no. 4-5, pp. 421-469, 2008.

[3] K. Wang and R. E. Dickinson, "A review of global terrestrial evapotranspiration: observation, modeling, climatology, and climatic variability," Reviews of Geophysics, vol. 50, no. 2, pp. 1-54, 2012

[4] X.-G. Wang, W. Wang, D. Huang, B. Yong, and X. Chen, "Modifying SEBAL model based on the trapezoidal relationship between land surface temperature and vegetation index for actual evapotranspiration estimation," Remote Sensing, vol. 6, no. 7, pp. 5909-5937, 2014.

[5] W. G. M. Bastiaanssen, M. Menenti, R. A. Feddes, and A. A. M. Holtslag, "A remote sensing surface energy balance algorithm for land (SEBAL). 1: formulation," Journal of Hydrology, vol. 212-213, pp. 198-212, 1998.

[6] R. G. Allen, M. Tasumi, and R. Trezza, "Satellite-based energy balance for mapping evapotranspiration with internalized calibration (METRIC)-model," Journal of Irrigation and Drainage Engineering, vol. 133, no. 4, pp. 395-406, 2007.

[7] Q. Mu, F. A. Heinsch, M. Zhao, and S. W. Running, "Development of a global evapotranspiration algorithm based on MODIS and global meteorology data," Remote Sensing of Environment, vol. 111, no. 4, pp. 519-536, 2007.

[8] Q. Mu, M. Zhao, and S. W. Running, "Improvements to a MODIS global terrestrial evapotranspiration algorithm," Remote Sensing of Environment, vol. 115, no. 8, pp. 1781-1800, 2011. 
[9] J. M. Norman, W. P. Kustas, and K. S. Humes, "Source approach for estimating soil and vegetation energy fluxes in observations of directional radiometric surface temperature," Agricultural and Forest Meteorology, vol. 77, no. 3-4, pp. 263-293, 1995.

[10] Y. Yang and S. Shang, "A hybrid dual-source scheme and trapezoid framework-based evapotranspiration model (HTEM) using satellite images: algorithm and model test," Journal of Geophysical Research: Atmospheres, vol. 118, no. 5, pp. 2284-2300, 2013.

[11] J. M. Sánchez, W. P. Kustas, V. Caselles, and M. C. Anderson, "Modelling surface energy fluxes over maize using a twosource patch model and radiometric soil and canopy temperature observations," Remote Sensing of Environment, vol. 112, no. 3, pp. 1130-1143, 2008.

[12] Z. Su, "The surface energy balance system (SEBS) for estimation of turbulent heat fluxes," Hydrology and Earth System Sciences, vol. 6, no. 1, pp. 85-100, 2002.

[13] D. Long and V. P. Singh, "A two-source trapezoid model for evapotranspiration (TTME) from satellite imagery," Remote Sensing of Environment, vol. 121, no. 2, pp. 370-388, 2012.

[14] W. G. M. Bastiaanssen, E. J. M. Noordman, H. Pelgrum, G. Davids, B. P. Thoreson, and R. G. Allen, "SEBAL model with remotely sensed data to improve water-resources management under actual field conditions," Journal of Irrigation and Drainage Engineering, vol. 131, no. 1, pp. 85-93, 2005.

[15] H. Su, M. F. Mccabe, E. F. Wood, Z. Su, and J. H. Prueger, "Modeling evapotranspiration during SMACEX: comparing two approaches for local- and regional-scale prediction," Journal of Hydrometeorology, vol. 6, no. 6, pp. 910-922, 2005.

[16] R. G. Allen, M. Tasumi, and A. Morse, "Satellite-based energy balance for mapping 834 evapotranspiration with internalized calibration (METRIC)-Applications," Journal of Irrigation and 835 Drainage Engineering, vol. 133, no. 4, pp. 395-406, 2007.

[17] J. Norman, M. Anderson, and W. Kustas, "Are single-source, remote-sensing surface-flux models too simple?," AIP Conference Proceedings, vol. 852, no. 170, 2006.

[18] W. P. Kustas, "Estimates of evapotranspiration with a oneand two-layer model of heat transfer over partial canopy cover," Journal of Applied Meteorology, vol. 29, no. 8, pp. 704-715, 1990.

[19] D. Troufleau, J. P. Lhomme, B. Monteny, and A. Vidal, "Sensible heat flux and radiometric surface temperature over sparse Sahelian vegetation. I: an experimental analysis of the $\mathrm{kB}^{-1}$ parameter," Journal of Hydrology, vol. 188-189, no. 1, pp. 815-838, 1997.

[20] W. J. Timmermans, W. P. Kustas, M. C. Anderson et al., “An intercomparison of the surface energy balance algorithm for land (SEBAL) and the two-source energy balance (TSEB) modeling schemes," Remote Sensing of Environment, vol. 108, no. 4, pp. 369-384, 2007.

[21] M. Anderson, J. M. Norman, G. R. Diak et al., "A two-source time-integrated model for estimating surface fluxes using thermal infrared remote sensing," Remote Sensing of Environment, vol. 60, no. 2, pp. 195-216, 1997.

[22] W. P. Kustas and J. M. Norman, "Evaluation of soil and vegetation heat flux predictions using a simple two-source model with radiometric temperatures for partial canopy cover," Agricultural and Forest Meteorology, vol. 94, no. 1, pp. 13-29, 1999.

[23] W. Kustas and M. Anderson, "Advances in thermal infrared remote sensing for land surface modeling," Agricultural and Forest Meteorology, vol. 149, no. 12, pp. 2071-2081, 2009.
[24] F. Li, W. P. Kustas, J. H. Prueger, C. M. U. Neale, and T. J. Jackson, "Utility of remote sensing-based two-source energy balance model under low- and high-vegetation cover conditions," Journal of Hydrometeorology, vol. 6, no. 6, pp. 878-891, 2005.

[25] E. Webster, D. Ramp, and R. T. Kingsford, "Spatial sensitivity of surface energy balance algorithms to meteorological data in a heterogeneous environment," Remote Sensing of Environment, vol. 187, pp. 294-319, 2016.

[26] M. Decker, M. A. Brunke, Z. Wang, K. Sakaguchi, X. Zeng, and M. G. Bosilovich, "Evaluation of the reanalysis products from GSFC, NCEP, and ECMWF using flux tower observations," Journal of Climate, vol. 25, no. 6, pp. 1916-1944, 2012.

[27] K. Nishida, R. R. Nemani, S. W. Running et al., "An operational remote sensing algorithm of land surface evaporation," Journal of Geophysical Research Atmospheres, vol. 108, no. D9, 2003.

[28] Y. Yao, S. Liang, J. Yu et al., "A simple temperature domain two-source model for estimating agricultural field surface energy fluxes from Landsat images," Journal of Geophysical Research, vol. 122, 2017.

[29] S. Liu, L. Lu, D. Mao, and L. Jia, "Evaluating parameterizations of aerodynamic resistance to heat transfer using field measurements," Hydrology and Earth System Sciences, vol. 11, no. 2, pp. 769-783, 2007.

[30] G. Y. Qiu, T. Yano, and K. Momii, “An improved methodology to measure evaporation from bare soil based on comparison of surface temperature with a dry soil surface," Journal of Hydrology, vol. 210, no. 1-4, pp. 93-105, 1998.

[31] Z. Sun, Q. Wang, B. Matsushita et al., "Development of a simple remote sensing evapotranspiration model (Sim-ReSET): algorithm and model test," Journal of Hydrology, vol. 376, no. 3-4, pp. 476-485, 2009.

[32] H. Sun, "Two-stage trapezoid: a new interpretation of the land surface temperature and fractional vegetation coverage space," IEEE Journal of Selected Topics in Applied Earth Observations and Remote Sensing, vol. 9, no. 1, pp. 336-346, 2016.

[33] R. Tang and Z. L. Li, "An end-member-based two-source approach for estimating land surface evapotranspiration from remote sensing data," IEEE Transactions on Geoscience \& Remote Sensing, vol. 55, no. 10, pp. 5818-5832, 2017.

[34] W. Wang, D. Huang, X.-G. Wang, Y.-R. Liu, and F. Zhou, "Estimation of soil moisture using trapezoidal relationship between remotely sensed land surface temperature and vegetation index," Hydrology and Earth System Sciences, vol. 15, no. 5, pp. 1699-1712, 2011.

[35] E. M. Blyth and R. J. Harding, "Application of aggregation models to surface heat flux from the Sahelian tiger bush," Agricultural \& Forest Meteorology, vol. 72, no. 3-4, pp. 213235, 1995.

[36] B. Choudhury, S. Idso, and R. Reginato, "Analysis of an empirical model for soil heat flux under a growing wheat crop for estimating evaporation by an infrared-temperature based energy balance equation," Agricultural and Forest Meteorology, vol. 39, no. 4, pp. 283-297, 1987.

[37] W. Brutsaert, Evaporation into the Atmosphere: Theory, History and Applications, Springer Science \& Business Media, Berlin, Germany, 2013.

[38] Z. Su, T. Schmugge, W. P. Kustas, and W. J. Kustas, "Two models for estimation of the roughness height for heat transfer between the land surface and the atmosphere," Journal of Applied Meteorology, vol. 40, no. 11, pp. 1933-1951, 2001. 
[39] W. J. Massman, ““A model study of $k B_{H}{ }^{-1}$ for vegetated surfaces using "localized near-field" Lagrangian theory," Journal of Hydrology, vol. 223, no. 1-2, pp. 27-43, 1999.

[40] X. Zeng, M. Barlage, R. E. Dickinson, Y. Dai, G. Wang, and K. Oleson, "Treatment of undercanopy turbulence in land models," Journal of Climate, vol. 18, no. 23, pp. 5086-5094, 2005.

[41] T. Carlson, "An overview of the "triangle method" for estimating surface evapotranspiration and soil moisture from satellite imagery," Sensors, vol. 7, no. 8, pp. 1612-1629, 2007.

[42] J. Levitt, Responses of Plants to Environmental Stresses, Academic Press, Cambridge, MA, USA, 1980.

[43] X. Li, S. Liu, Q. Xiao et al., "A multiscale dataset for understanding complex eco-hydrological processes in a heterogeneous oasis system," Scientific Data, vol. 4, no. 1, Article ID 170083, 2017.

[44] X. Wen, B. Yang, X. Sun, and X. Lee, "Evapotranspiration partitioning through in-situ oxygen isotope measurements in an oasis cropland," Agricultural \& Forest Meteorology, vol. 230-231, pp. 89-96, 2016.

[45] C. Liebethal, B. Huwe, and T. Foken, "Sensitivity analysis for two ground heat flux calculation approaches," Agricultural and Forest Meteorology, vol. 132, no. 3-4, pp. 253-262, 2005.

[46] T. E. Twine, W. P. Kustas, J. M. Norman et al., "Correcting eddy-covariance flux underestimates over a grassland," $A g$ ricultural and Forest Meteorology, vol. 103, no. 3, pp. 279-300, 2000.

[47] L. Song, S. Liu, W. P. Kustas et al., "Application of remote sensing-based two-source energy balance model for mapping field surface fluxes with composite and component surface temperatures," Agricultural and Forest Meteorology, vol. 230231, pp. 8-19, 2016.

[48] Z. Jiang, A. Huete, K. Didan, and T. Miura, "Development of a two-band enhanced vegetation index without a blue band," Remote Sensing of Environment, vol. 112, no. 10, pp. 38333845, 2008.

[49] H. Li, D. Sun, Y. Yu et al., "Evaluation of the VIIRS and MODIS LST products in an arid area of Northwest China," Remote Sensing of Environment, vol. 142, no. 1, pp. 111-121, 2014.

[50] Y. Li, C. Huang, J. Hou, J. Gu, G. Zhu, and X. Li, “Mapping daily evapotranspiration based on spatiotemporal fusion of ASTER and MODIS images over irrigated agricultural areas in the Heihe river basin, Northwest China," Agricultural and Forest Meteorology, vol. 244-245, pp. 82-97, 2017.

[51] X. Pan, Y. Liu, and X. Fan, "Satellite retrieval of surface evapotranspiration with nonparametric approach: accuracy assessment over a semiarid region," Advances in Meteorology, vol. 2016, Article ID 1584316, 14 pages, 2016.

[52] T. Xu, S. M. Bateni, S. A. Margulis, L. Song, S. Liu, and Z. Xu, "Partitioning evapotranspiration into soil evaporation and canopy transpiration via a two-source variational data assimilation system," Journal of Hydrometeorology, vol. 17, no. 9, pp. 2353-2370, 2016.

[53] Y. Song, L. Jin, G. Zhu, and M. Ma, "Parameter estimation for a simple two-source evapotranspiration model using Bayesian inference and its application to remotely sensed estimations of latent heat flux at the regional scale," Agricultural and Forest Meteorology, vol. 230-231, pp. 20-32, 2016.

[54] Y. Yang, D. Long, H. Guan, W. Liang, C. Simmons, and O. Batelaan, "Comparison of three dual-source remote sensing evapotranspiration models during the MUSOEXE-12 campaign: revisit of model physics," Water Resources Research, vol. 51, no. 5, pp. 3145-3165, 2015.
[55] C. Huang, Y. Li, J. Gu, L. Lu, and X. Li, "Improving estimation of evapotranspiration under water-limited conditions based on SEBS and MODIS data in arid regions," Remote Sensing, vol. 7, no. 12, pp. 16795-16814, 2015.

[56] Y. Ma, S. Liu, F. Zhang et al., "Estimations of regional surface energy fluxes over heterogeneous oasis-desert surfaces in the middle reaches of the Heihe river during HiWATERMUSOEXE," IEEE Geoscience \& Remote Sensing Letters, vol. 12, no. 3, pp. 671-675, 2015.

[57] Q. Zhuang and B. Wu, "Estimating evapotranspiration from an improved two-source energy balance model using ASTER satellite imagery," Water, vol. 7, no. 12, pp. 6673-6688, 2015.

[58] L. Song, S. Liu, X. Zhang et al., "Estimating and validating soil evaporation and crop transpiration during the HiWATERMUSOEXE," IEEE Geoscience and Remote Sensing Letters, vol. 12, no. 2, pp. 334-338, 2015.

[59] G. F. Zhu, X. Li, Y. H. Su et al., "Simultaneously assimilating multivariate data sets into the two-source evapotranspiration model by Bayesian approach: application to spring maize in an arid region of northwestern China," Geoscientific Model Development, vol. 7, no. 4, pp. 1467-1482, 2014.

[60] M. S. Moran, T. R. Clarke, Y. Inoue, and A. Vidal, "Estimating crop water deficit using the relation between surface-air temperature and spectral vegetation index," Remote Sensing of Environment, vol. 49, no. 3, pp. 246-263, 1994.

[61] S. D. Prince and S. N. Goward, "Global primary production: a remote sensing approach," Journal of Biogeography, vol. 22, no. 4-5, pp. 815-835, 1995.

[62] J. Wang, J. Zhuang, W. Wang, S. Liu, and Z. Xu, “Assessment of uncertainties in eddy covariance flux measurement based on intensive flux matrix of HiWATER-MUSOEXE," IEEE Geoscience \& Remote Sensing Letters, vol. 12, no. 2, pp. 259263, 2015

[63] D. Baldocchi, J. Finnigan, K. Wilson et al., "On measuring net ecosystem carbon exchange over tall vegetation on complex terrain," Boundary-Layer Meteorology, vol. 96, no. 1-2, pp. 257-291, 2000.

[64] C. Liebethal and T. Foken, "Evaluation of six parameterization approaches for the ground heat flux," Theoretical \& Applied Climatology, vol. 88, no. 1-2, pp. 43-56, 2007.

[65] M. A. Friedl, "Relationships among remotely sensed data, surface energy balance, and area-averaged fluxes over partially vegetated land surfaces," Journal of Applied Meteorology, vol. 35, no. 11, pp. 2091-2103, 1996.

[66] W. P. Kustas, X. Zhan, and T. J. Schmugge, "Combining optical and microwave remote sensing for mapping energy fluxes in a semiarid watershed," Remote Sensing of Environment, vol. 64, no. 2, pp. 116-131, 1998.

[67] K. Yang and J. Wang, "A temperature prediction-correction method for estimating surface soil heat flux from soil temperature and moisture data," Science in China Series D: Earth Sciences, vol. 51, no. 5, pp. 721-729, 2008.

[68] W. P. Kustas and J. M. Norman, "A two-source approach for estimating turbulent fluxes using multiple angle thermal infrared observations," Water Resources Research, vol. 33, no. 6, pp. 1495-1508, 1997.

[69] J. P. Lhomm, B. Montenya, and M. Amadoua, "Estimating sensible heat flux from radiometric temperature over sparse millet," Agricultural \& Forest Meteorology, vol. 68, no. 1-2, pp. 77-91, 1994.

[70] R. Zhang, J. Tian, H. Su, X. Sun, S. Chen, and J. Xia, "Two improvements of an operational two-layer model for terrestrial surface heat flux retrieval," Sensors, vol. 8, no. 10, pp. 6165-6187, 2008. 
[71] X. Zhan, W. P. Kustas, and K. S. Humes, "An intercomparison study on models of sensible heat flux over partial canopy surfaces with remotely sensed surface temperature," Remote Sensing of Environment, vol. 58, no. 3, pp. 242-256, 1996.

[72] Y. Wu, T. Du, F. Li, S. Li, R. Ding, and L. Tong, "Quantification of maize water uptake from different layers and root zones under alternate furrow irrigation using stable oxygen isotope," Agricultural Water Management, vol. 168, pp. 35-44, 2016.

[73] J. M. Norman and F. Becker, "Terminology in thermal infrared remote sensing of natural surfaces," Remote Sensing Reviews, vol. 12, no. 3-4, pp. 153-166, 1995.

[74] P. D. Colaizzi, W. P. Kustas, M. C. Anderson et al., "Twosource energy balance model estimates of evapotranspiration using component and composite surface temperatures," Advances in Water Resources, vol. 50, no. 6, pp. 134-151, 2012.

[75] F. Tian, G. Qiu, Y. Yang, Y. Lü, and Y. Xiong, "Estimation of evapotranspiration and its partition based on an extended three-temperature model and MODIS products," Journal of Hydrology, vol. 498, no. 1, pp. 210-220, 2013.

[76] A. Chehbouni, Y. Nouvellon, J.-P. Lhomme et al., "Estimation of surface sensible heat flux using dual angle observations of radiative surface temperature," Agricultural and Forest Meteorology, vol. 108, no. 1, pp. 55-65, 2001.

[77] K. S. Humes, W. P. Kustas, M. S. Moran, W. D. Nichols, and M. A. Weltz, "Variability of emissivity and surface temperature over a sparsely vegetated surface," Water Resources Research, vol. 30, no. 5, pp. 1299-1310, 1994.

[78] W. P. Kustas, J. M. Norman, T. J. Schmugge et al., "Mapping surface energy fluxes with radiometric temperature," in Thermal remote sensing in land surface processes, CRC Press, New York, NY, USA, 2004.

[79] R. Allen, A. Irmak, R. Trezza, J. M. H. Hendrickx, W. Bastiaanssen, and J. Kjaersgaard, "Satellite-based ET estimation in agriculture using SEBAL and METRIC," $H y$ drological Processes, vol. 25, no. 26, pp. 4011-4027, 2011.

[80] Y. Yang, H. Su, R. Zhang, J. Tian, and L. Li, “An enhanced two-source evapotranspiration model for land (ETEML): algorithm and evaluation," Remote Sensing of Environment, vol. 168 , no. 168 , pp. 54-65, 2015.

[81] M. C. Anderson, J. M. Norman, W. P. Kustas et al., "Effects of vegetation clumping on two source model estimates of surface energy fluxes from an agricultural landscape during SMACEX," Journal of Hydrometeorology, vol. 6, no. 6, p. 892, 2005.

[82] H. Guan and J. L. Wilson, "A hybrid dual-source model for potential evaporation and transpiration partitioning," Journal of Hydrology, vol. 377, no. 3-4, pp. 405-416, 2009.

[83] R. D. Jackson, S. B. Idso, R. J. Reginato, and P. J. Pinter, "Canopy temperature as a crop water stress indicator," Water Resources Research, vol. 17, no. 4, pp. 1133-1138, 1981.

[84] A. Vidal and A. Perrier, "Technical note Analysis of a simplified relation for estimating daily evapotranspiration from satellite thermal IR data," International Journal of Remote Sensing, vol. 10, no. 8, pp. 1327-1337, 1989. 